\title{
Inferring Monetary Policy Objectives with a Partially Observed State
}

\author{
Gregory E. Givens ${ }^{\mathrm{a}, *}$, Michael K. Salemi ${ }^{\mathrm{b}}$

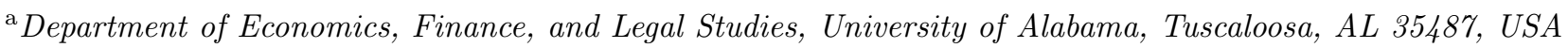 \\ ${ }^{\mathrm{b}}$ Department of Economics, University of North Carolina, Chapel Hill, NC 27599-3305, USA
}

First Draft: May 2012

\begin{abstract}
Accounting for the uncertainty inherent in real-time perceptions of the state of the economy is believed to be critical for the analysis of historical monetary policy. We investigate this claim through the lens of a small-scale new-Keynesian model with optimal discretionary policy and partial information about the state. The model is estimated using maximum likelihood on US data over the Volcker-Greenspan-Bernanke regime. A comparison of our estimates to those from a version of the model with complete information reveals that under partial information: $(i)$ the Federal Reserve demonstrates a significant concern for stabilizing fluctuations in the output gap, and (ii) the discrepancy between optimal and observed policy behavior is smaller.
\end{abstract}

Keywords: Partial Information, Optimal Monetary Policy, Central Bank Preferences JEL Classification: E37, E52, E58, E61, C61

\footnotetext{
*Corresponding author. Tel.: + 2053488961.

E-mail address: gegivens@cba.ua.edu (G.E. Givens).
} 


\section{Introduction}

Central banks face the difficult task of conducting monetary policy in situations where realtime uncertainty about the state of the economy is pervasive. Uncertainty of this kind has two sources. One is the "noise" contained in preliminary measures of economic activity, such as output and inflation, that are used by policymakers to forecast the state. Data on these variables are continually revised over time, so the true values are not known until long after they are first released and policy decisions have been made (e.g., Croushore and Stark, 2001). A second source of uncertainty concerns estimates of economic concepts that are not directly observable but still play a vital role in the policy process. The natural rates of output and unemployment are prominent examples. Forming inferences about these variables requires a statistical model that specifies how they are related to observed data. Given the uncertainty over such models and in published data, it is common for real-time estimates of the natural rates to be way off the mark (e.g., Kuttner, 1994; Orphanides and van Norden, 2002).

Because monetary policy depends on the central bank's current perception of the state of the economy, correctly interpreting historical policy behavior demands that one account for the type of informational limitations described above. Athanasios Orphanides was one of the first to point this out in a series of influential papers (e.g., Orphanides, 2001; 2002; 2004) that questioned the value of policy analysis based on data and concepts other than what policymakers actually encountered at the time decisions were being made. Using the simple rule proposed by Taylor (1993) as an example, Orphanides (2001) showed that policy recommendations implied by real-time data are often at odds with those obtained from $e x$ post revised data. Moreover, estimating such rules using only the latest information can obscure one's view of the way monetary authorities reacted to economic conditions as they appeared at the time. To identify the policy motives of the past, it is thus imperative to understand what the central bank was seeing at the moment their policies were implemented. 
The papers written by Orphanides belong to a large literature that uses the Taylor rule as a means of describing historical monetary policy (e.g., Clarida, Galí, and Gertler, 2000). Yet, some have argued that these rules are hard to interpret because the feedback coefficients do not map uniquely into the "deep" parameters that represent the preferences of the policy authority. The key insight is that Taylor-type rules can be derived endogenously by solving an explicit optimization problem for the central bank (e.g., Svensson, 1997). It follows that estimated policy-rule coefficients may depend on the various weights in the central bank's objective function in addition to the parameters characterizing the structure of the economy. Disentangling the two requires an econometric procedure that specifically acknowledges the policymaker's optimization problem during the course of estimation (e.g., Favero and Rovelli, 2003; Ozlale, 2003; Dennis, 2006; Salemi, 2006). The usual strategy adopted in this literature is to estimate a model of private behavior subject to the restriction that monetary policy is optimal. Such an exercise enables one to obtain joint estimates of the structural parameters and the weights in the policy objective function that identify central bank preferences.

To date, most of the papers that try to explain policy as the outcome of an optimization problem assume that private agents and the central bank are perfectly informed about the state of the economy. Since there is no conflict between real-time and revised concepts under perfect information, the models featured in this literature are typically estimated with ex post revised data. However, this type of analysis appears as vulnerable to the Orphanides critique as analyses based on the Taylor rule, which treats central bank behavior as a primitive rather than the product of rational optimization. By endowing agents with full information and ignoring the intrinsic uncertainty of real-time data, the researcher is viewing history through a distorted lens. Attempts to validate such a model empirically may produce biased estimates of the economic structure and, in particular, the policy objective function.

Our paper continues the line of research dating back to Salemi (1995) that estimates 
the parameters of the central bank's objective function. ${ }^{1}$ However, we break from standard practice by utilizing a model in which agents only have partial knowledge of the state. Every period private agents and the central bank derive an optimal estimate of the state vector by filtering information contained in a small set of noisy indicators. The central bank then implements an optimal policy conditional on its current beliefs while the private sector forms expectations consistent with the chosen policy. Thus in our model economic decisions depend on real-time perceptions of the state instead of the actual state as would be the case under complete information. The optimal-filtering (signal-extraction) mechanism also provides a way to track the evolution of these perceptions through time. Orphanides (2004) contends that both features are essential for correctly identifying historical policy objectives.

Estimation is performed on a simple new-Keynesian model of output-inflation dynamics. The concept of natural output has a dual role; it appears as an exogenous forcing variable in the Phillips curve and as the target for real output in the policy objective function. Regarding the information structure, we assume that private agents and the central bank observe noisy current-period measures of output growth, inflation, and the unemployment rate, the latter of which is linked to the model through an Okun's Law relationship. Using the methodological approach outlined in Svensson and Woodford (2003), both sets of agents obtain an efficient estimate of the state vector by means of a Kalman-filter updating equation. Given its estimate of the state, the central bank sets the nominal interest rate to minimize a weighted quadratic loss function under discretion. The arguments in the loss function include deviations of inflation and output from target and changes in the interest rate.

To estimate our partial information model, we employ a data set that combines real-time and ex post revised data spanning the Federal Reserve chairmanships of Volcker, Greenspan, and Bernanke. Using real-time data to estimate the loss function is a departure from much of

\footnotetext{
${ }^{1}$ Early examples in this literature are Cecchetti, McConnell, and Perez-Quiros (2002), Dennis (2004), Söderström, Söderlind, and Vredin (2005), and Cecchetti, Flores-Lagunes, and Krause (2006). More recent contributions include Givens and Salemi (2008), Ilbas (2012), and Givens (2012).
} 
the extant literature that relies exclusively on revised data (e.g., Dennis, 2006; Ilbas, 2012). In those studies omitting noisy real-time data makes sense because agents are assumed to know the true value of the state at each point in time. By contrast, our model recognizes a distinction between the true state variables and the group of indicators that agents observe in real time. The consistent approach here is to identify the former with ex post revised data but the latter with data that was actually available when past decisions were made.

In short, the goal of this paper is to underscore the empirical consequences of placing information constraints on a model with optimal monetary policy. To fully achieve that goal, we take a page from the previous literature by estimating a second model that differs only in its assumption that agents have complete knowledge of the state of the economy. We then report those estimates alongside our benchmark estimates obtained under partial information. Comparing results across the two models clarifies the effect that informational assumptions have on estimates of the structural parameters and loss function weights.

Our findings suggest that uncertainty about the state has a major impact on inferences concerning the output objective in the policy loss function. Under partial information the weight on the output gap term (i.e., the gap between actual output and the natural rate) relative to inflation exceeds one-fourth and is statistically significant. Under complete information the relative weight on output gap stability is small and not significantly different from zero, echoing results from previous studies that disregard informational frictions altogether.

Estimates of the policy equation reveal that conflict between fitting the observed interest rate path and satisfying the restrictions imposed by discretionary policy is greatly diminished in the partial information version of our model. We base this conclusion on various tests of the hypothesis that policy was optimal during the sample period. Specifically, we employ a likelihood ratio test as well as the Bayesian information criterion and a related pseudo-posterior odds ratio to assess the fit of the optimal-policy model compared to a nested alternative that leaves the policy equation free. Results from all three show that 
the discrepancy between the two policies is considerably smaller in a partial information framework, implying that optimal and historical monetary policy are more easily reconciled under partial information than under complete information.

A key step in establishing the validity of our partial information mechanism is checking whether the uncertainties are sufficient to generate meaningful perception errors over time. If the estimated model tells us that real-time perceptions of the state were never far from the true state, then accounting for partial information may offer scant improvement over full information in efforts to identify historical policy motives. We perform this check by estimating past output gap and inflation misperceptions with the Kalman smoother. Estimates reveal that beliefs about the state were at times very different from reality, particularly with regard to the output gap. Moreover, variance decompositions show that output gap misperceptions were mainly driven by shocks to the natural rates of output and unemployment while inflation misperceptions were largely the result of cost-push shocks and indicator noise.

\subsection{Related Literature}

Our paper is part of a growing literature that incorporates partial information into a newKeynesian framework. Dotsey and Hornstein (2003) and Coenen, Levin, and Wieland (2005) assess the information content of money using models calibrated to US and euro area data, respectively. Both studies find that money provides little information about the state of the economy that is useful for stabilization policy. Ehrmann and Smets (2003) and Cukierman and Lippi (2005) characterize optimal policy under conditions where the true value of natural output is unknown. The information problem causes agents to make systematic prediction errors when estimating the output gap, which in turn biases the policy setting away from a full information benchmark. ${ }^{2}$ Dellas (2006) and Collard and Dellas (2010) show that

\footnotetext{
${ }^{2}$ Aoki (2003) studies optimal monetary policy under similar conditions and finds that partial information justifies a more cautious response to noisy indicators.
} 
mismeasurement of the state along with a forecasting rule derived from the Kalman filter helps the new-Keynesian model produce an inertial response of inflation to monetary shocks. Collard, Dellas, and Smets (2009) use Bayesian methods to estimate a DSGE model with the same type of information structure. They find that partial information acts as an endogenous propagation mechanism and improves the fit of the model in terms of log likelihood.

The paper that is perhaps closest to ours is Lippi and Neri (2007). They too estimate a model with partial information and optimal discretionary policy, but our analysis differs from their's in many important ways. First, we estimate our model with US data, whereas Lippi and Neri estimate on euro area data. Second, Lippi and Neri only report estimates under partial information because their main emphasis is on comparing the signal quality of real money balances and unit labor costs. Our task is to examine the implications of partial information per se, so we also consider a complete information model and report the two sets of estimates side-by-side. Third, Lippi and Neri estimate their model with ex post revised data alone. We use both real-time and ex post revised data simultaneously during estimation. Exploiting the information present in real-time data should yield a more accurate depiction of historical policy, as argued by Orphanides (2001) and Croushore (2011).

Few studies in this literature employ real-time data during the course of estimation. Neri and Ropele (2011) is a recent example of one that does. They apply Bayesian methods to estimate a new-Keynesian model with partial information à la Svensson and Woodford (2003). There are two key areas in which our paper departs from their's. First, Neri and Ropele represent policy with a Taylor rule and use the estimated model to compute the implied output gap-inflation volatility tradeoff facing the European Central Bank. We restrict policy to be the outcome of optimal discretion in order to recover the weights in the Federal Reserve's loss function. Second, Neri and Ropele estimate partial and complete information versions of their model using either ex post revised or real-time data separately. They do not consider a version that uses both types of data at the same time. 


\section{An Empirical Model with Partial Information}

This section presents a new-Keynesian model with partial information and optimal discretionary policy. We define partial information as the inability of economic agents to perfectly observe the state. Thus the information problem is restricted to items in the state vector; the model and its parameters are known with certainty. Each period agents update their beliefs with the arrival of new information (i.e., data) on the indicator variables, which include measures of output growth, inflation, and the unemployment rate. The economic structure consists of an IS equation, a Phillips curve, a stochastic process for natural output, an Okun's Law relationship, and a loss function describing the stabilization goals of monetary policy.

\subsection{The IS Equation}

The aggregate demand component of the model is characterized by an IS equation

$$
y_{t}=\phi y_{t+1 \mid t-1}+(1-\phi)\left[\beta y_{t-1}+(1-\beta) y_{t-2}\right]-\sigma\left(i_{t-1}-\pi_{t \mid t-1}\right)+\varepsilon_{y, t},
$$

where $y_{t}$ is real output, $i_{t}$ is the one-period nominal interest rate, $\pi_{t}$ is the inflation rate, and $\varepsilon_{y, t}$ is a demand shock, assumed to be $i . i . d . N\left(0, \sigma_{y}^{2}\right)$. For any variable $z_{t}, z_{\tau \mid t}$ denotes $E\left[z_{\tau} \mid \Omega_{t}\right]$, the expected value (optimal prediction) of $z_{\tau}$ conditional on the date- $t$ information set $\Omega_{t}$. In our model the policymaker and private agents have symmetric information.

When $\phi=1$ Eq. (1) resembles the modern new-Keynesian specification of aggregate demand based on the consumption Euler equation, in which $\sigma$ is the intertemporal elasticity of substitution (e.g., Rotemberg and Woodford, 1997). Augmenting the IS equation with

lags $(\phi<1)$ represents a departure from strict micro-foundations but is necessary to capture persistent aspects of the data, as discussed by Estrella and Fuhrer (2002). Following Rudebusch (2002), Eq. (1) contains an explicit lag in the transmission from the ex ante 
real interest rate to output and on the information set for expectations formation. Svensson (1997) asserts that these kinds of adjustment and processing lags, which together give rise to a delayed reaction of output to changes in policy, are crucial aspects of monetary policy that should feature prominently in models of inflation targeting.

\subsection{The Phillips Curve}

Inflation dynamics are governed by a Phillips curve

$$
\pi_{t}=\alpha \pi_{t+1 \mid t-1}+(1-\alpha) \pi_{t-1}+\kappa\left(y_{t-1}-y_{t-1}^{n}\right)+\varepsilon_{\pi, t}
$$

which relates inflation to past and expected future inflation and the output gap, defined as the deviation of actual output from its natural level. The conceptual framework for Eq. (2) is a model of monopolistically competitive firms that adjust prices infrequently. The cyclical factor determining the size of price adjustments is real marginal cost, which varies proportionately with the output gap under certain conditions (e.g., Woodford, 2003). In such an environment, parameter $\kappa$ is inversely related to the duration of price fixity. The variable $\varepsilon_{\pi, t}$ is viewed as an exogenous "cost-push" shock and is assumed to be i.i.d. $N\left(0, \sigma_{\pi}^{2}\right)$.

The rationale for including lagged inflation $(\alpha<1)$ is mainly empirical. Fuhrer $(1997)$ argues that purely forward-looking Phillips curves produce "jump" dynamics for inflation that are at odds with the type of inertial responses evident in the data. As in Rudebusch (2002), we embed a transmission lag from the output gap to inflation and an information lag in the dating of expectations. The combination of these two ensures that current inflation is predetermined and that policy changes affect prices by altering expected future inflation one period before being transmitted through the output gap. ${ }^{3}$

Natural output $y_{t}^{n}$ plays a central role in the model, both as a driving force for inflation

\footnotetext{
${ }^{3} \mathrm{~A}$ shift in $i_{t}$ has an immediate impact on $\pi_{t+2 \mid t}$, which in turn affects the equilibrium value of $\pi_{t+1}$.
} 
and as a target for monetary policy. As is standard in the new-Keynesian literature, we view natural output as the level that prevails in the absence of sticky prices and market power. The key difference here is that agents do not observe $y_{t}^{n}$ directly, but instead must estimate it every period by solving a particular signal-extraction problem. Although values of $y_{t}^{n}$ are unseen, its stochastic process is known with certainty. Specifically, natural output follows

$$
y_{t}^{n}=\theta y_{t-1}^{n}+\varepsilon_{n, t}+\eta_{y} \varepsilon_{y, t}
$$

where $|\theta|<1$. Fluctuations in $y_{t}^{n}$ originate from two different shocks. The first shock, $\varepsilon_{n, t}$, immediately affects the state of natural output and is assumed to be i.i.d. $N\left(0, \sigma_{n}^{2}\right)$. Numerous studies interpret this kind of shock as a productivity innovation (e.g., Clarida, Galí, and Gertler, 1999). The second shock is the demand shock, $\varepsilon_{y, t}$, which enters the law of motion for $y_{t}^{n}$ with coefficient $\eta_{y} \geq 0$. In a general equilibrium setting with nominal rigidities, natural output is driven by supply (productivity) and demand shocks, the latter of which can be attributed to things like shifts in consumer preferences (e.g., Erceg, Henderson, and Levin, 2000). Permitting correlation between natural output and aggregate demand shocks is consistent with the theoretical framework that underlies this class of models.

\subsection{Okun's Law}

The data used to estimate simple new-Keynesian models is usually limited to measures of real output, inflation, and a nominal interest rate (e.g., Lubik and Schorfheide, 2004; Lindé, 2005). In the real world, however, central banks and market participants forecast the state by filtering information from numerous economic variables that are not always present in stylized models (e.g., Boivin and Giannoni, 2006). To partially capture this dynamic, we

augment Eqs. (1) - (3) with an equation linking the unemployment rate, a key indicator of cyclical conditions, to the output gap. This allows unemployment data to be used by agents 
for signal extraction and by the econometrician for estimating the structural parameters.

Unemployment enters the model by means of an Okun's Law relationship

$$
u_{t}-u_{t}^{n}=-\chi\left(y_{t}-y_{t}^{n}\right)
$$

where $u_{t}$ and $u_{t}^{n}$ are the actual and natural rates of unemployment. Natural unemployment is understood to be the rate at which there is no incipient pressure on inflation stemming from imbalances between $y_{t}$ and $y_{t}^{n}$. Eqs. (2) and (4) imply that when $u_{t}=u_{t}^{n}$, the only forces acting on inflation are "cost-push" shocks. ${ }^{4}$ Like $y_{t}^{n}$, we assume that $u_{t}^{n}$ is not observable, but its stochastic process is part of $\Omega_{t}$. We follow Staiger, Stock, and Watson (2001) in describing natural unemployment as a random walk: $u_{t}^{n}=u_{t-1}^{n}+\varepsilon_{u, t}$, and $\varepsilon_{u, t}$ is i.i.d. $N\left(0, \sigma_{u}^{2}\right)$.

When there is no uncertainty about the state of the economy, unemployment is irrelevant for policy since it has no causal role in the dynamics of other variables and is not an argument in the loss function (see below). In the more realistic case where uncertainty exists, however, unemployment may carry useful information on unobservable components of the state that are important for stabilization, such as the natural level of output. It follows that changes in the unemployment rate that are thought to reflect movements in payoff-relevant variables indirectly affect the dynamics of the model by inducing shifts in the policy instrument.

\subsection{The Loss Function}

The central bank selects $i_{t}$ each period to minimize the loss function

$$
\mathcal{L}_{t}=E\left[(1-\delta) \sum_{j=0}^{\infty} \delta^{j}\left\{\pi_{t+j}^{2}+\lambda_{y}\left(y_{t+j}-y_{t+j}^{n}\right)^{2}+\lambda_{i}\left(i_{t+j}-i_{t+j-1}\right)^{2}\right\} \mid \Omega_{t}\right]
$$

\footnotetext{
${ }^{4}$ Our definition of natural unemployment differs somewhat from the long-run concept of Friedman (1968) and Phelps (1968), who describe it as the unemployment rate to which an economy would converge given structural features of the labor market. While our model does not explain the determinants of long-run unemployment, the fact that the Phillips curve coefficients on past and future inflation sum to one implies that it is consistent with the Phelps-Friedman natural rate hypothesis.
} 
where $\delta \in(0,1)$. Eq. (5) embodies the preferences of a policymaker whose goals are to stabilize inflation and output around their target values and to achieve a smooth path for the interest rate. The inflation target is assumed to be constant and is normalized to zero. The time-varying output target is given by the natural level of output $y_{t}^{n}$. The "smoothing" term $\lambda_{i}\left(i_{t+j}-i_{t+j-1}\right)^{2}$, which penalizes big swings in the policy instrument, is empirically compelling because it helps account for the serial correlation apparent in interest rate data (e.g., Söderström et al., 2005). Parameters $\lambda_{y} \geq 0$ and $\lambda_{i} \geq 0$ are the weights on the output gap and interest-rate smoothing objectives relative to inflation. Together they characterize the preferences of monetary policy since their values determine how much the central bank trades off one stabilization goal for another. The loss function weights are the key objects of interest in this paper. As such, they are treated as free parameters that are to be estimated jointly with the coefficients of the structural model.

\subsection{The Indicator Variables}

Economic agents have limited information on the state of the economy. At the beginning of each period, they receive signals on three variables from which they must infer the true value of the full state vector. The first two signals, or indicators, are noisy measures of output growth and inflation represented by

$$
\begin{aligned}
\Delta y_{t}^{o} & =\Delta y_{t}+v_{g, t} \\
\pi_{t}^{o} & =\pi_{t}+v_{p, t},
\end{aligned}
$$

where $v_{g, t}$ and $v_{p, t}$ are measurement shocks that capture the noise in the observations of $\Delta y_{t}$ and $\pi_{t}$ first released (e.g., by a statistical agency) in period $t .^{5}$ We allow for possible serial

\footnotetext{
${ }^{5} \Delta$ denotes the first difference operator.
} 
correlation in the measurement errors by modeling them as autoregressive processes

$$
\begin{aligned}
& v_{g, t}=\rho_{g} v_{g, t-1}+\varepsilon_{g, t} \\
& v_{p, t}=\rho_{p} v_{p, t-1}+\varepsilon_{p, t},
\end{aligned}
$$

where $\left|\rho_{g}\right|<1,\left|\rho_{p}\right|<1, \varepsilon_{g, t} \sim$ i.i.d. $N\left(0, \sigma_{g}^{2}\right)$, and $\varepsilon_{p, t} \sim$ i.i.d. $N\left(0, \sigma_{p}^{2}\right)$.

Measurement shocks affect the information problem that agents confront in a significant way. Suppose that $\sigma_{g}=\sigma_{p}=0$, implying that the true values of output and inflation were observable. It is clear from the IS equation that market participants and the central bank would be able to perfectly derive aggregate demand shocks each period. Furthermore, the only uncertainty surrounding inflation would be in distinguishing cost-push shocks from shocks to natural output. When both indicators are contaminated with noise (i.e., $\sigma_{g}, \sigma_{p}>$ 0 ), identifying the sources of aggregate fluctuations is more challenging and subject to greater uncertainty. An observed change in output growth could be due to a demand shock or a measurement shock. Similarly, an increase in inflation could be the result of rising output, declining natural output, a cost-push shock, or a positive measurement shock. Given their knowledge of the economy, information-constrained agents assign certain probabilities to each of these scenarios in forming an optimal estimate of the state.

The third indicator is the unemployment rate $u_{t}$. Because it depends on the true output gap via Okun's Law, unemployment can have significant information content in a setting where agents receive noisy signals on output growth and inflation and natural output is unknown. However, $u_{t}$ also varies in response to unobserved shifts in the natural rate of unemployment $u_{t}^{n}$, which degrades the quality of the information it provides on current output gap conditions. In fact, observations on $u_{t}$ are uninformative in the course of forecasting the state if the variance of $u_{t}^{n}$ is large. This turns out to be the case in our model because the natural rate follows a random walk, implying that the variance of $u_{t}^{n}$ is unbounded. As a 
practical matter, we first difference Eq. (4) to obtain

$$
\Delta u_{t}=-\chi\left(y_{t}-y_{t}^{n}\right)+\chi\left(y_{t-1}-y_{t-1}^{n}\right)+\varepsilon_{u, t},
$$

and assume that agents observe the change in the unemployment rate $\Delta u_{t}$. Knowledge of $\Delta u_{t}$ is potentially valuable since fluctuations in $\varepsilon_{u, t}$ are stationary. Thus one implication of modeling $u_{t}^{n}$ as a random walk process is that the information content of the unemployment rate actually resides in the first difference of this series.

\section{Optimal Policy and Signal Extraction}

Using the notation in Svensson and Woodford (2003), we express the model compactly as

$$
\left[\begin{array}{c}
X_{t+1} \\
\Gamma x_{t+1 \mid t}
\end{array}\right]=A^{1}\left[\begin{array}{c}
X_{t} \\
x_{t}
\end{array}\right]+A^{2}\left[\begin{array}{c}
X_{t \mid t} \\
x_{t \mid t}
\end{array}\right]+B i_{t}+\left[\begin{array}{c}
N \varepsilon_{t+1} \\
\mathbf{0}_{2 \times 1}
\end{array}\right]
$$

where $X_{t}=\left[\begin{array}{lllllllll}y_{t} & \pi_{t} & y_{t}^{n} & y_{t-1} & i_{t-1} & y_{t-1}^{n} & \varepsilon_{u, t} & v_{g, t} & v_{p, t}\end{array}\right]^{\prime}$ are the date- $t$ predetermined variables, $x_{t}=\left[y_{t+1 \mid t} \pi_{t+1 \mid t}\right]^{\prime}$ are the date- $t$ forward-looking variables, $i_{t}$ is the policy instrument, and $\varepsilon_{t+1}=\left[\begin{array}{llllll}\varepsilon_{y, t+1} & \varepsilon_{\pi, t+1} & \varepsilon_{n, t+1} & \varepsilon_{u, t+1} & \varepsilon_{g, t+1} & \varepsilon_{p, t+1}\end{array}\right]^{\prime}$ are the $i . i . d$. shocks with covariance matrix $\Sigma$. The parameters of the model appear as elements of the matrices $A^{1}, A^{2}, B, \Gamma$, and $N{ }^{6}$

The policymaker and the private sector do not have full information about the state of the economy, that is, about the individual elements of $X_{t}$ and $x_{t}$. Instead, they only observe the indicator variables, collected in a vector $Z_{t}$, which can be used to form optimal predictions of $X_{t}$ and $x_{t}$ at each point in time. In this model the indicators are related to the state by

$$
Z_{t}=D X_{t}
$$

\footnotetext{
${ }^{6}$ Appendix A shows how Eqs. (1) - (10) can be mapped into the general linear-quadratic form used by Svensson and Woodford (2003).
} 
where $Z_{t}=\left[\Delta y_{t}^{o} \pi_{t}^{o} \Delta u_{t}\right]^{\prime}$ and $D$ is a $(3 \times 9)$ selection matrix. ${ }^{7}$ The information set available to agents in period $t$ is thus $\Omega_{t} \equiv\left\{Z_{\tau}, \tau \leq t ; A^{1}, A^{2}, B, \Gamma, N, D, \Sigma, \delta, \lambda_{y}, \lambda_{i}\right\}$.

Eq. (12) is a special case of the general formulation used by Svensson and Woodford (2003) in which $Z_{t}$ contains both predetermined and forward-looking variables. Forwardlooking indicators complicate the signal-extraction problem because they depend, by definition, on expected future endogenous variables. These expectations, in turn, depend on an estimate of the state, which is itself a function of the indicators. The authors develop new techniques to handle this circularity issue and present the results in terms of a modified Kalman filter. ${ }^{8}$ In our model all of the indicator variables are predetermined. As a result, the standard Kalman filter is sufficient for computing optimal forecasts of the state vector. ${ }^{9}$

\subsection{Optimization under Discretion}

The central bank conducts optimal monetary policy under discretion. As such, it minimizes the loss function period-by-period subject to Eq. (11) conditional on $\Omega_{t}$. The equilibrium is one in which the policy functions depend only on current predetermined variables.

Svensson and Woodford (2003) show that the policy setting and estimates of the forwardlooking variables depend linearly on current estimates of the predetermined variables,

$$
\begin{aligned}
i_{t} & =F X_{t \mid t}, \\
x_{t \mid t} & =G X_{t \mid t},
\end{aligned}
$$

\footnotetext{
${ }^{7}$ Note that $v_{g, t}$ and $v_{p, t}$ are embedded in $X_{t}$ rather than appearing as explicit shocks to Eq. (12).

${ }^{8}$ These findings extend work by Pearlman, Currie, and Levine (1986) showing that estimation of the state can be obtained by means of a Kalman filter in forward-looking models with partial symmetric information.

${ }^{9} \mathrm{~A}$ case involving forward-looking indicators is examined in Appendix C, where we estimate a version of the model that removes all transmission and information lags so that current output and inflation are no longer predetermined. The estimation results are broadly similar to the ones reported in section 5 .
} 
where $F$ solves a particular matrix Ricatti equation, $G$ is a fixed point of the relation

$$
G=\left(A_{22}-\Gamma G A_{12}\right)^{-1}\left[\left(\Gamma G A_{11}-A_{21}\right)+\left(\Gamma G B_{1}-B_{2}\right) F\right]
$$

and $\left\{A_{11}, A_{12}, A_{21}, A_{22}, B_{1}, B_{2}\right\}$ are the partitions of $A \equiv A^{1}+A^{2}$ and $B$ with dimensions conformable to $X_{t}$ and $x_{t}$. Substituting Eq. (14) into the lower block of Eq. (11) gives

$$
x_{t}=G^{1} X_{t}+G^{2} X_{t \mid t},
$$

with $G^{1}=-\left(A_{22}^{1}\right)^{-1} A_{21}^{1}$ and $G^{2}=G-G^{1}$. It follows that predetermined variables obey

$$
X_{t+1}=H X_{t}+J X_{t \mid t}+N \varepsilon_{t+1},
$$

where $H=A_{11}^{1}+A_{12}^{1} G^{1}$ and $J=A_{12}^{1} G^{2}+A_{11}^{2}+A_{12}^{2} G+B_{1} F$.

\subsection{Optimal Filtering}

To fully characterize the dynamics of the endogenous variables, the law of motion for $X_{t \mid t}$ must be specified. Since none of the forward-looking variables are observable, estimates of the predetermined variables can be obtained from a standard Kalman filter. The recursive updating equation expressed in terms of innovations to $X_{t}$ is given by

$$
X_{t \mid t}=X_{t \mid t-1}+K D\left(X_{t}-X_{t \mid t-1}\right),
$$

where the steady-state gain matrix $K=P D^{\prime}\left(D P D^{\prime}\right)^{-1}$. The matrix $P$ is the covariance of the prediction error $X_{t}-X_{t \mid t-1}$ which satisfies $P=H\left[P-P D^{\prime}\left(D P D^{\prime}\right)^{-1} D P\right] H^{\prime}+N \Sigma N^{\prime}$. 
Finally, taking conditional expectations of Eq. (16) gives

$$
X_{t+1 \mid t}=(H+J) X_{t \mid t},
$$

which completes the description of equilibrium dynamics under partial information. ${ }^{10}$

A benefit of modeling the optimal-filtering problem is that it provides an estimate of the Kalman gain matrix. ${ }^{11}$ The elements of this matrix correspond to the weights agents put on innovations in the various indicators when revising their forecasts of the predetermined variables. In other words, $K$ describes how new information is used in updating beliefs about the state. Interestingly, the filtering weights can be determined without reference to the policymaker's control problem. Note that the equations for $K$ and $P$ imply that the gain matrix depends on $A^{1}, D, N$, and $\Sigma$ but not on $\lambda_{y}, \lambda_{i}$, or $\delta$. This illustrates the well-known separation principle in linear-quadratic models with partial information (e.g., LeRoy and Waud, 1977). Specifically, the best estimate of the state is independent of the chosen policy.

\section{Estimation Strategy}

The equilibrium under partial information admits a state-space representation that can be estimated with maximum likelihood using the Kalman filter (e.g., Harvey, 1989). As in Lippi and Neri (2007), the state vector appropriate for estimation is formed by augmenting the predetermined variables $X_{t}$ with conditional forecasts $X_{t \mid t-1}$. Thus for our model the state is an $(18 \times 1)$ object $\mathbf{s}_{t} \equiv\left[X_{t}^{\prime} X_{t \mid t-1}^{\prime}\right]^{\prime}$ whose dynamics are governed by a transition equation

$$
\mathbf{s}_{t+1}=\mathbf{M} \mathbf{s}_{t}+\mathbf{N} \varepsilon_{t+1} .
$$

\footnotetext{
${ }^{10}$ Appendix A provides a derivation of the Kalman-filter updating equation for this model.

${ }^{11}$ An estimate of the gain matrix $K$ is presented in Appendix D along with a brief discussion of the results.
} 
Elements of the $(18 \times 18)$ matrix $\mathbf{M}$ and the $(18 \times 6)$ matrix $\mathbf{N}$ are functions of the structural

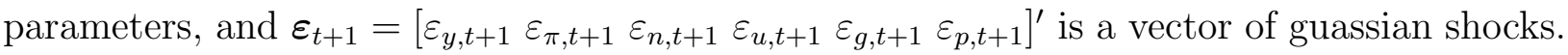
Estimation requires modeling the joint evolution of $X_{t}$ and $X_{t \mid t-1}$ since these two vectors are determined simultaneously by Eqs. (16) and (18) after substituting out $X_{t \mid t}$ using Eq. (17).

Closing the state-space model is a measurement equation linking variables observed by the econometrician to the state $\mathbf{s}_{t}$. Unlike economic agents who only observe the indicators $Z_{t}=\left[\begin{array}{llll}\Delta y_{t}^{o} & \pi_{t}^{o} & \Delta & u_{t}\end{array}\right]^{\prime}$ along with the policy rate $i_{t}$, we assume that the econometrician sees not just $Z_{t}$ and $i_{t}$ but also the true values of output growth $\Delta y_{t}$ and inflation $\pi_{t}$. This is a departure from Lippi and Neri (2007) and Neri and Ropele (2011) who require that economic agents and the econometrician always observe the same data.

Our choice to give the researcher an expanded data set that includes $\Delta y_{t}$ and $\pi_{t}$ recognizes the distinction between economic decision making, a process carried out in real time, and model estimation, which is an exercise in retrospection. It is well known that real-time data, a concept made explicit in our model through the role of indicators, are often revised as more comprehensive information becomes available and as measurement techniques improve. With the benefit of hindsight, the econometrician should be able to condition estimation on revised data even though such data would not have been accessible to agents in real time. Below we argue that ex post revised data, while not perfect, are the best available measures of the true variables that the structural model seeks to explain but that agents never fully observe.

Defining $\mathbf{y}_{t} \equiv\left[\Delta y_{t}^{o} \pi_{t}^{o} \Delta u_{t} i_{t} \Delta y_{t} \pi_{t}\right]^{\prime}$, the measurement equation takes the form

$$
\mathbf{y}_{t}=\mathbf{T} \mathbf{s}_{t}+\mathbf{u}_{t}
$$

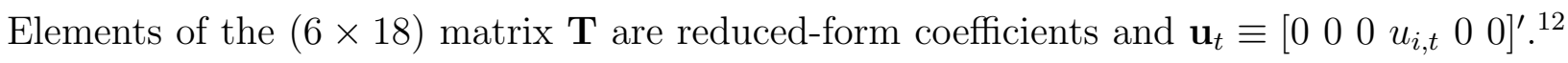
The variable $u_{i, t}$ is a measurement shock with distribution i.i.d. $N\left(0, \sigma_{i}^{2}\right)$; it represents the

\footnotetext{
${ }^{12}$ Appendix A shows how to derive Eqs. (19) and (20) and how to construct matrices M, N, and T.
} 
"stochastic wedge" between the sample interest rate and the rate prescribed by optimal discretion. The role of $u_{i, t}$ is to circumvent the stochastic singularity that would occur if the observed interest rate responded only to $\mathbf{s}_{t}$ (e.g., Ingram, Kocherlakota, and Savin, 1994).

Estimation requires data for the variables in $\mathbf{y}_{t}$ observed by agents and those seen exclusively by the econometrician. In choosing $\Delta y_{t}^{o}$ and $\pi_{t}^{o}$, we follow Orphanides (2001) who argues that real-time data accurately represent the information that was available to policymakers and market participants who were around at the time economic decisions were being made. Our data source is the Real-Time Data Set for Macroeconomists published by the Federal Reserve Bank of Philadelphia. ${ }^{13}$ We define $\Delta y_{t}^{o}$ as the annualized first difference of the log of seasonally-adjusted real output (ROUTPUTQvQd), converted to per-capita terms by subtracting the log growth rate of the civilian noninstitutional population. In constructing this series, we take the last output growth calculation from each "vintage" of data published (quarterly) over the sample period. Using the same procedure, readings on the annualized first difference of the log of the seasonally-adjusted output deflator (PQvQd) provide our measure of $\pi_{t}^{o} \cdot{ }^{14}$

The data used to assemble real-time measures of output growth and inflation undergo a continual process of revision in the months and years following their initial release (e.g., Croushore and Stark, 2001). As a result, the "true" values of these concepts remain unknown for a long time after the date of first publication. In light of this fact, we assume that observations of $\Delta y_{t}$ and $\pi_{t}$ correspond to "final" published data, that is, the complete time series as recorded in the latest available release. ${ }^{15}$ Of course, even final data is subject to

\footnotetext{
${ }^{13} \mathrm{http}$ // www.philadelphiafed.org/research-and-data/real-time-center/real-time-data/

${ }^{14} \mathrm{We}$ have assumed that error-prone measures of output growth and inflation are observed by agents contemporaneously, even though preliminary data from the national income and product accounts is actually released with a one-quarter lag. We estimated a version of the model that accounts for the publication lag by setting $Z_{t}=\left[\begin{array}{lll}\Delta y_{t-1}^{o} & \pi_{t-1}^{o} \Delta u_{t}\end{array}\right]^{\prime}$. The results were very similar to the ones reported here.

${ }^{15}$ We choose not to model the nature or timing of data revisions in this paper. Instead, the cumulative effect of the full history of revisions to any given data point are encapsulated in our model by the measurement shocks $v_{g, t}$ and $v_{p, t}$, defined as the difference between real-time observations of output growth and inflation and their final values. Although agents are unable to perfectly infer $v_{g, t}$ and $v_{p, t}$ like the econometrician
} 
uncertainty and will likely be revised again in the future. Nevertheless, we view it as offering the most reliable account of the true historical profiles of output growth and inflation. ${ }^{16}$

Finally, the information structure implies that private agents and the econometrician have the same data on unemployment and the nominal interest rate. Our measure for $i_{t}$ is the annual yield on three-month US Treasury bills. For the unemployment series we use the seasonally-adjusted civilian unemployment rate (RUC). Our assumption that agents observe the true value of $\Delta u_{t}$ in real time is based on reports showing that revisions to unemployment data are usually small, infrequent, and confined to seasonal factors (e.g., Kozicki, 2004).

Fig. 1 plots the historical time series for the variables in the econometrician's data set. Each one has been de-meaned prior to estimation, except for $\Delta u_{t}$ whose sample mean is very near zero to begin with. Observations on output growth, inflation, and the interest rate are therefore interpreted as annual percentage points less their sample averages. Readings on $\Delta u_{t}$ are expressed as percentage-point changes in the quarterly unemployment rate. Rather than display the actual series for $\Delta y_{t}^{o}$ and $\pi_{t}^{o}$, Fig. 1 plots the differences between real-time and final revised values for output growth and inflation. Viewing the real-time data in this way makes it easier to spot periods where large ex post revisions occurred.

Our sample period runs from 1979:Q3 - 2010:Q1, dates that span the Federal Reserve chairmanships of Paul Volcker, Alan Greenspan, and Ben Bernanke. The conventional wisdom is that a fundamental shift in US monetary policy occurred soon after Volcker's appointment in August 1979. Since we do not address the possibility of structural breaks in the policy parameters, we estimate our model over a period of time that can be plausibly characterized as having a stable monetary regime.

can, they have complete knowledge of their stochastic properties when forecasting the state.

${ }^{16}$ The series for $\Delta y_{t}$ and $\pi_{t}$ are based on historical data published during the final quarter of 2010. At the time of writing, the 2010:Q4 vintage was the most up-to-date and allowed for two consecutive revisions to the last observation in our sample. 


\subsection{A Model with Complete Information}

Throughout the paper we will be comparing results of the partial information model to those from a version that assumes complete information. Under complete information agents have full knowledge of the state of the economy at all times. This is accomplished by setting the matrix $D$ in Eq. (12) equal to the identity matrix, so that the true values of all predetermined variables are seen each period. ${ }^{17}$ Clearly, full information obviates the signal-extraction problem used to track agents' beliefs when information is incomplete. As a result, the equilibrium with discretionary policy can be found by applying standard solution methods for linear-quadratic control problems without a filtering component (e.g., Söderlind, 1999).

Another difference between partial and complete information concerns the data used for estimation. When agents know the true values of $\Delta y_{t}$ and $\pi_{t}$, the measurement shocks in Eqs. (6) and (7) vanish (i.e., $\sigma_{g}=\sigma_{p}=0$ ). Using real-time data on output growth and inflation along with the true values as recorded in the latest data vintage would render the model stochastically singular because $\Delta y_{t}^{o}=\Delta y_{t}$ and $\pi_{t}^{o}=\pi_{t}$ in this case. Consequently, we drop $\Delta y_{t}^{o}$ and $\pi_{t}^{o}$ from the measurement equation and estimate the model using only data on unemployment, the interest rate, and the revised series for output growth and inflation.

\section{$5 \quad$ Empirical Findings}

\subsection{Parameter Estimates}

Table 1 displays maximum-likelihood estimates and standard errors of the parameters appearing in Eqs. (1) - (10). ${ }^{18}$ The first column presents estimates for the benchmark model under partial information. The second column presents estimates for the case in which the

\footnotetext{
${ }^{17} \mathrm{~A}$ more detailed exposition of the complete information model can be found in Appendix B.

${ }^{18}$ Robust standard errors are computed as the square roots of the diagonal elements of the variancecovariance matrix proposed by White (1982).
} 
policymaker and private agents have complete information on the state of the economy.

There are many similarities but also some important differences between estimates of the partial and complete information models. Looking first at the structural shocks, estimates of $\sigma_{y}$ and $\sigma_{\pi}$ indicate that demand shocks are about one-third less volatile than cost-push shocks in both models. Estimates of $\sigma_{n}$, however, reveal that shocks to natural output are almost twice as volatile under partial information. Moreover, the impact of demand shocks on natural output as measured by $\eta_{y}$ is weaker when agents have limited information. The estimate of $\eta_{y}$ is 0.32 in this case compared to 0.46 under full information. Regarding shocks to the natural rate of unemployment, the estimate of $\sigma_{u}$ is 0.08 under partial information but 0.17 under complete information. Both are statistically significant despite their small size relative to other shocks in the model.

Estimating the partial information model with real-time data enables us to identify the measurement shocks $v_{g, t}$ and $v_{p, t}$ in Eqs. (6) and (7). Estimates of $\sigma_{g}$ and $\sigma_{p}$ reveal that the noise component of $\pi_{t}^{o}$ is larger on average than that of $\Delta y_{t}^{o}$. Both estimates are also statistically significant and of the same order of magnitude as the "fundamental" shocks entering the IS equation and the Phillips curve. We also find little evidence of serial correlation. Estimates of $\rho_{g}$ and $\rho_{p}$ are in the neighborhood of zero and statistically insignificant.

The partial and complete information models have fairly similar implications for the IS and Phillips curves but differ somewhat with regard to Okun's Law. Estimates of $\phi$, for example, are close to one-third, implying that both lagged and expected future output play a key role in the IS equation. Estimates of $\sigma$, the interest-rate elasticity of output, are small but significant only in the partial information case. Estimates of $\alpha$ are around one-half, which suggests that past and future inflation are equally important for explaining current inflation in the Phillips curve. Estimates of the output gap elasticity $\kappa$ are small and imprecise but within the range typical of the literature (e.g., Kiley, 2007). Finally, the estimate of the Okun coefficient $\chi$ is 0.38 under partial information, which is about 20 percent smaller than 
the corresponding estimate under complete information.

Turning to the loss function, the estimate of $\lambda_{i}$ is 0.76 in the partial information model but only 0.16 under complete information. ${ }^{19}$ Although the difference between the estimates may be economically significant, the standard errors suggest that neither is statistically different from zero. Our results contrast those reported by Dennis (2004), Söderström et al. (2005), and Dennis (2006) showing that optimal and observed policy actions can be reconciled with a large and significant weight on interest-rate smoothing, albeit in a full information environment. Incorporating limited information in the present model evidently helps raise the smoothing penalty. Nevertheless, the uncertainty surrounding our estimate of $\lambda_{i}$ makes it difficult to draw precise conclusions about the past concern for interest-rate smoothing as an explicit policy goal. Studies that find similar evidence include Favero and Rovelli (2003), Salemi (2006), and Givens (2012).

Where information restrictions have a more clear-cut impact is on inferences concerning the output gap objective. The estimate of $\lambda_{y}$ under partial information is 0.27 with a standard error of 0.12 , while under complete information the estimate is 0.15 and the standard error 0.50. Thus macroeconomic outcomes, if viewed from the perspective of the partial information model, are consistent with the notion that policymakers place significant weight on stabilizing the output gap. This is an important result because it points to a different interpretation of historical policy motives than would otherwise emerge had we confined our analysis to the case of full information. It may also provide an answer for why studies often find $\lambda_{y}$ to be insignificant (e.g., Dennis, 2006; Salemi, 2006) despite public statements from leading central bankers suggesting that output and inflation are independently important as exemplified by the Federal Reserve's "dual mandate" (e.g., Mishkin, 2007). Our findings suggest that it could be due to the failure of these studies to account for the type of

\footnotetext{
${ }^{19}$ We fix the discount factor $\delta=0.99$ prior to estimation. Stress tests showed that the remaining estimates are not overly sensitive to small variations in $\delta$ for either model.
} 
information constraints that policymakers face in real time.

To further assess the significance of the output stabilization goal, we conduct likelihood ratio tests of the hypothesis that $\lambda_{y}=0$. Significance tests that rely on standard errors can be distorted by inaccuracies in evaluating the Hessian. When estimates of the restricted model are available, a likelihood ratio test is preferred because it does not reference standard errors. Columns three and four of Table 1 report estimates for the partial and complete information models under the restriction $\lambda_{y}=0 .{ }^{20}$ Omitting the output gap under partial information lowers log likelihood from -671.25 to -675.56 , producing a chi-square statistic of 8.61 ( $p$ value $<0.01)$. Applying the same procedure to the complete information model generates a chi-square statistic of 0.08 ( $p$-value is 0.78 ). The hypothesis that $\lambda_{y}=0$ is therefore rejected by the data in the partial information case. By contrast, the complete information model appears to fit the data equally well with or without an output gap term in the loss function.

To recap, we find that incorporating uncertainty into the model in the form of a partially observed state changes the estimates of certain parameters in a significant way. Chief among them is the relative weight on the output gap in the central bank's loss function, which is nearly twice as large and far more precise under partial information than under complete information. Estimates of some of the non-policy parameters are also sensitive to the information structure, notably the Okun coefficient and the variances of the shocks to natural output and unemployment. Taken together, our results lend support to the central argument put forward by Orphanides (2001) and illustrate the importance of basing historical analysis on realistic assumptions about the information available to decision makers in real time.

\footnotetext{
${ }^{20}$ In the complete information model the null hypothesis is $\lambda_{y}=1 \mathrm{e}-5$. Initial attempts at estimating the model with $\lambda_{y}=0$ caused $\left(\kappa, \lambda_{i}\right) \rightarrow(0,0)$, producing an indeterminate equilibrium under discretionary policy. We found that $\lambda_{y}=1 \mathrm{e}-5$ was small enough to form inferences about the statistical contribution of $\lambda_{y}$ without causing our estimates to drift into the indeterminacy region of the parameter space.
} 


\subsection{Tests of Policy Optimality}

A central task of this paper is to determine whether our partial information framework can resolve the conflict between optimal policy and observed policy that has been frequently reported in the literature (e.g., Rudebusch, 2001; Dennis, 2006; Salemi, 2006). One way to accomplish this is to formally test the parameter restrictions implied by discretionary policy in both the partial and complete information models. This involves estimating the model once with the optimal-policy restrictions imposed and once with those restrictions relaxed and then testing whether the model fits the data equally well in the two cases. If accounting for imperfect information helps to reconcile historical and optimal policy, we should find it harder (in a statistical sense) to reject the optimality hypothesis under partial information than under complete information.

To organize a valid test of the optimal-policy restrictions, we estimate a version of the model that does not force central bank actions to be the product of loss minimization. Specifically, we replace Eq. (5) with an unconstrained rule for the interest rate that fixes distinct response coefficients to the predetermined variables comprising the state. This arrangement nests optimal discretion as a special case since the latter results from conditioning estimation on the requirement that policy-rule coefficients jointly minimize the loss function. Table 2 displays estimates of the policy coefficients under partial and complete information. In both cases we report the unrestricted estimates, obtained by relaxing the coefficient restrictions tied to loss minimization, as well as the optimal coefficients implied by discretionary policy. ${ }^{21}$

It is immediately clear that the discrepancy between optimal and unrestricted policy is much smaller in the partial information case than in the complete information case. Under partial information optimal responses to perceived inflation and the lagged interest rate are nearly identical to their unrestricted counterparts. The policy restrictions also do not appear to have a significant effect on responses to perceived levels of current and past out-

\footnotetext{
${ }^{21}$ Standard errors of the discretionary coefficients are obtained using the delta method.
} 
put. Responses to perceived changes in natural output, however, are a bit smaller (less accommodative) under optimal policy than under an unrestricted policy.

The picture is very different in the complete information case, where imposing optimal policy substantially alters some of the coefficient estimates. For example, discretion calls for a much weaker countercyclical response to output and tighter monetary conditions following a rise in natural output.

The tension between fitting the data and satisfying the optimal-policy criteria can also be seen in estimates of the structural parameters reported in Table 3. Notice there are only a few parameters in the partial information case for which the estimates recovered under discretion are significantly different from those associated with the unrestricted policy. These include the shocks to natural output $\sigma_{n}$ and unemployment $\sigma_{u}$ and perhaps the IS parameters $\phi$ and $\beta$. The contrast is more prominent under complete information. Notably, estimates of $\phi$ and $\beta$ point to greater forward-looking emphasis in the IS curve when policy is unconstrained, and estimates of $\sigma_{n}$ and $\theta$ indicate less volatility and persistence in shocks to natural output.

Because the models in each comparison group are nested, we can evaluate the optimalpolicy hypothesis using a likelihood ratio test. Under partial information log likelihood is -665.59 when policy is unrestricted compared to -671.25 when it is optimal. Since there are 5 free policy-rule coefficients in the former but only 2 loss function weights in the latter, discretion places 3 restrictions on the model. Thus the chi-square statistic is 11.32 ( $p$-value is 0.0101 ), indicating that the data reject the optimality hypothesis at the $5 \%$ significance level but not at the $1 \%$ level. Under complete information the policy restrictions decrease log likelihood from -406.90 to -445.17 , producing a chi-square statistic of 76.53 ( $p$-value $<0.0001)$. We therefore reject the null with a high degree of confidence in this case.

Another way to evaluate the optimal-policy hypothesis is with the Bayesian information criterion. The $B I C$ has a couple of advantages over a likelihood ratio test. First, it penalizes log likelihood according to the number of free parameters in the model. This often makes 
the $B I C$ a more robust indicator of fit since it is always possible to increase likelihood by adding parameters, even though such a procedure may lead to overfitting instead of actual gains in predictive performance. Second, the $B I C$ is asymptotically equivalent to the Bayes estimator under certain conditions (e.g., Schwarz, 1978), thereby providing a measure of the model's posterior odds. As explained by Kiley (2007), a pseudo-posterior probability can be formed by using the $B I C$ as a substitute for marginal likelihood in the ratio

$$
\mathcal{M}(j)=\frac{\exp (B I C(j))}{\sum_{h=1}^{m} \exp (B I C(h))},
$$

where $\mathcal{M}(j)$ denotes the conditional probability of some candidate model $j$ among the $m$ different models being considered. Although it has a Bayesian interpretation, the pseudoodds ratio depends only on the discrepancy between the approximating model and the data, adjusted for degrees of freedom, and not on any prior beliefs about the parameter or model space. This follows from the implicit use of equal model priors in the formation of $\mathcal{M}$ and from the independence between the $B I C$ and priors over the parameters of each model.

Log likelihood, the $B I C$, and the posterior model probabilities are displayed in Table 3. Under partial information the $B I C$ is -718.53 for the unrestricted policy but -716.97 for optimal discretion. Between these two candidates, the pseudo-odds criterion points to an $83 \%$ probability of the discretionary model given the available data. The opposite occurs under complete information. Loosening the optimal-policy restrictions raises the $B I C$ from -481.26 to -450.21 , resulting in a near zero posterior probability of the discretionary model.

The results presented in this section echo the findings of Rudebusch (2001) who shows that incorporating real-time uncertainty about the output gap and inflation is critical in efforts to interpret historical policy as the outcome of a loss minimization problem. Interestingly, the similarities emerge despite some important conceptual and methodological differences between our two studies. One difference is that Rudebusch uses a simple two- 
parameter Taylor rule to characterize monetary policy, whereas we consider a wider class of policies in which the interest rate reacts to all of the variables in the state vector. ${ }^{22}$ Our paper also differs in the procedure for identifying the best-fitting optimal policy. Rudebusch derives optimal Taylor-rule coefficients using a fixed structural model and loss function for the central bank and then searches over the right mix of uncertainties until the resulting policy coefficients match the historical ones. By contrast, we impose on the underlying model a specific information constraint and then search over eligible values of the structural parameters and loss function weights for the combination that maximizes log likelihood.

\subsection{Historical Misperceptions}

Our decision to model the central bank's information problem recognizes the fact that policymakers face considerable uncertainty about the state of the economy in real time. Under such conditions policy actions will reflect current perceptions of the state rather than its true value. Correctly interpreting historical policy, so the argument goes, requires that one take into account how those perceptions have evolved through time. Yet, implicit in this argument is the assumption that beliefs about the state are often far from reality; if not, policy behavior would be very similar to the behavior suggested by estimates based on revised data and perfect information. It follows that if agents' perception errors are negligible, using a model that distinguishes the true state from real-time estimates of the state may not be important for obtaining valid inferences of the structural parameters and loss function weights. We investigate this concern by deriving historical estimates of the misperceptions that actually occurred over the sample period as seen through the partial information model. A quantitative assessment of the size and nature of those misperceptions can provide evidence on whether incorporating partial information as described above is critical for the type

\footnotetext{
${ }^{22}$ Excluding a constant intercept term, the policy rule used in Rudebusch (2001) can be obtained in our model by restricting $\gamma_{y}=-\gamma_{n}$ and $\gamma_{y y}=\gamma_{i}=0$.
} 
of policy analysis carried out in this paper.

In estimating the path of historical misperceptions, we focus on two variables that jointly summarize most of the information in the state vector: the output gap and inflation. ${ }^{23}$ To be clear, by misperceptions we mean differences between the true paths of the output gap and inflation, $\left\{q_{t}, \pi_{t}\right\}_{t=1}^{T}$, and the paths perceived by agents in the model, $\left\{q_{t \mid t}, \pi_{t \mid t}\right\}_{t=1}^{T}$. We use the fixed interval Kalman smoother as described in de Jong (1989) on Eqs. (19) and (20) to estimate both the true and perceived series from 1979:Q3 to 2010:Q1. Unlike the "one-sided" estimates produced by the standard Kalman filter, the smoother generates "twosided" estimates that reflect data contained in the full sample. We denote the sequence of these estimates as $\left\{\hat{q}_{t}, \hat{\pi}_{t}, \hat{q}_{t \mid t}, \hat{\pi}_{t \mid t}\right\}_{t=1}^{T}$. Thus for any period $t$, the estimated output gap misperception is given by $\hat{q}_{t \mid t}-\hat{q}_{t}$ and the inflation misperception by $\hat{\pi}_{t \mid t}-\hat{\pi}_{t}$.

Figs. 2 and 3 plot the actual and perceived estimates of the output gap and inflation, respectively, as well as the corresponding real-time perceptions errors. Summary statistics on each of these series are reported in Table 4. Regarding the output gap, our estimates point to significant variation in agents' misperceptions over time, ranging from -1.59 percentage points in 1999:Q4 to 0.45 in 2010:Q1. Estimates of $q_{t \mid t}-q_{t}$ also appear to exhibit substantial serial correlation. The first-order autocorrelation coefficient of this series is 0.93 , meaning that errors in forecasting the output gap tended to persist for many periods. Indeed, from the end of the 1991 recession to the beginning of the most recent "Great Recession," agents underestimated the output gap by no less than 0.49 percentage points every quarter. ${ }^{24}$

Real-time estimates of the output gap are also clearly biased in the Volcker-GreenspanBernanke era. The mean difference between $\hat{q}_{t \mid t}$ and $\hat{q}_{t}$ is -0.78 percentage points, indicating that monetary authorities systematically underestimated prevailing output gap conditions.

\footnotetext{
${ }^{23}$ In this section we denote the output gap as $q_{t} \equiv y_{t}-y_{t}^{n}$.

${ }^{24}$ This finding lends empirical support to the theoretical results in Cukierman and Lippi (2003) demonstrating that retrospective errors in forecasting the output gap are generally serially correlated in models with optimal monetary policy and partial symmetric information.
} 
This result is consistent with the evidence in Orphanides (2003, 2004) showing that the Federal Reserve's assessment of the output gap in real time was uniformly lower than its true value as recognized ex post throughout the 1980s and early 1990s. Our estimates suggest that this bias continued until 2009:Q3. Finally, it is worth noting that fluctuations in the perception errors tend to be cyclical. Estimates of $q_{t \mid t}-q_{t}$ peak (in absolute value) at the end of expansions and shrink during recessions.

Estimates of actual and perceived inflation displayed in Fig. 3 reveal a different pattern of misperceptions than those surrounding the output gap. For example, there is little indication of any bias or serial correlation in estimates of the inflation misperceptions. The average spread between $\hat{\pi}_{t \mid t}$ and $\hat{\pi}_{t}$ in the sample is only 0.01 percentage points, and the autocorrelation coefficient of $\hat{\pi}_{t \mid t}-\hat{\pi}_{t}$ is 0.28 . Nevertheless, errors in forecasting inflation were considerable at times, reaching highs of 2.52 percentage points in 2008:Q4 and lows of -2.07 in 1981:Q1. The overall volatility of $\hat{\pi}_{t \mid t}-\hat{\pi}_{t}$ is nontrivial; the standard deviation of this series is 0.72 percent. Interestingly, our findings are again quite comparable to the historical account of the Federal Reserve's outlook for inflation as documented in Orphanides (2003, 2004). During the 1980s and 1990s, it was not uncommon for real-time estimates of inflation to be off by 1 or 2 percentage points. However, records also show that the Fed did not make systematic errors like they did in forecasting the output gap, and inflation misperceptions typically vanished after a few quarters.

An advantage of using a structural model to estimate historical misperceptions is that it allows one to identify the economic shocks most responsible for the observed variation. The papers written by Orphanides are largely silent on this matter because real-time concepts are constructed ex ante from primary source data and without reference to an explicit model. In particular, misperceptions are obtained by subtracting real-time data published in the Federal Reserve's Greenbook from corresponding ex post revised data. ${ }^{25}$ As a result,

\footnotetext{
${ }^{25}$ The Greenbook is prepared by the Federal Reserve Board staff before each meeting of the Federal Open
} 
Orphanides can only speculate on the key determinants of historical variation in the perception errors. In our setup agents process incoming data efficiently when forecasting the state. Misperceptions are thus endogenous and depend on the underlying model as well as the quality of information extracted from the indicators. This feature makes the partial information model a useful device for examining the contribution of individual shocks to the variability of policy misperceptions over time.

Table 5 decomposes the variances of $q_{t \mid t}-q_{t}$ and $\pi_{t \mid t}-\pi_{t}$ into shares attributed to each of the model's six orthogonal shocks. Decompositions are reported at one-year, three-year, and ten-year forecast horizons. The results indicate that shocks to the natural rates of output and unemployment account for 90 to 95 percent of the short and long-run variance of output gap misperceptions. Demand shocks and the noise component of output growth jointly explain the remaining 5 to 10 percent. Cost-push shocks and the noise in observed inflation, on the other hand, have little impact on mismeasurement of the output gap in real time. In contrast to the output gap, errors in forecasting inflation are driven almost entirely by cost-push shocks and inflation noise. The other four shocks account for a negligible fraction of the prediction error variance at usual business cycle frequencies.

\section{Concluding Remarks}

This paper reports estimates from a new-Keynesian model of output-inflation dynamics with optimal discretionary policy under two different assumptions about the structure of information. In the first case market participants and the central bank only have partial (symmetric) knowledge about the underlying state of the economy. Each period they form an optimal estimate of the state by filtering the information contained in a small set of noisy indicator variables. In the the second case agents are assumed to have complete knowledge

Market Committee. It reports projections for the current and future macroeconomic outlook, which are made available to the public after a five-year lag. 
of the state at all times. We estimate these two versions of the model separately using a maximum-likelihood procedure with quarterly US data spanning the chairmanships of Volcker, Greenspan, and Bernanke. Examining both sets of estimates side-by-side sheds light on the various ways in which accounting for informational limitations modifies our understanding of the economic structure and, in particular, the objectives of monetary policy.

Our results show that partial information changes estimates of the Federal Reserve's loss function and helps reconcile the conflict between optimal and observed policy over the sample. Specifically, the weight on output gap stability relative to inflation is large and significant under partial information but small and imprecise under full information. A likelihood-based assessment of the restrictions imposed by optimal discretion indicates that partial information also improves the fit of the optimal-policy model in comparison to a nested alternative that leaves policy unrestricted. In other words, optimal and historical policy appear to be more compatible under partial information than under complete information.

To evaluate the economic significance of our findings, we use the Kalman smoother on the partial information model to recover historical estimates of both the true and perceived values of the output gap and inflation. Estimates reveal that past perceptions of the state were at times a far cry from reality. Moreover, real-time perception errors, particularly those associated with the output gap, were likely to persist for many quarters. This divergence between the perceived state and the true state exposes the magnitude of informational problems that policymakers face and, therefore, the importance for proper historical analysis of building realistic forms of uncertainty into macroeconometric models of optimal policy. 


\section{References}

Aoki, Kosuke. "On the Optimal Monetary Policy Response to Noisy Indicators." Journal of Monetary Economics, April 2003, 50(3), pp. 501-23.

Boivin, Jean and Giannoni, Marc. "DSGE Models in a Data-Rich Environment." NBER Working Paper No. 12772, December 2006.

Cecchetti, Stephen G.; Flores-Lagunes, Alfonso and Krause, Stefan. "Has Monetary Policy Become More Efficient? A Cross-Country Analysis." The Economic Journal, April 2006, 116(511), pp. 408-33.

Cecchetti, Stephen G.; McConnell, Margaret M. and Perez-Quiros, Gabriel. "Policymakers' Revealed Preferences and the Output-Inflation Variability Tradeoff: Implications for the European System of Central Banks." The Manchester School, June 2002, 70(4), pp. 596-618.

Clarida, Richard; Galí, Jordi and Gertler, Mark. "The Science of Monetary Policy: A New Keynesian Perspective." Journal of Economic Literature, December 1999, 37(4), pp. 1661-707.

. "Monetary Policy Rules and Macroeconomic Stability: Evidence and Some Theory." The Quarterly Journal of Economics, February 2000, 115(1), pp. 147-80.

Coenen, Günter; Levin, Andrew and Wieland, Volker. "Data Uncertainty and the Role of Money as an Information Variable for Monetary Policy." European Economic Review, May 2005, 49(4), pp. 975-1006.

Collard, Fabrice and Dellas, Harris. "Monetary Misperceptions, Output, and Inflation Dynamics." Journal of Money, Credit and Banking, March/Arpil 2010, 42(2-3), pp. 483502.

Collard, Fabrice; Dellas, Harris and Smets, Frank. "Imperfect Information and the Business Cycle." Journal of Monetary Economics, October 2009, 56(S), pp. 38-56.

Croushore, Dean. "Frontiers of Real-Time Data Analysis." Journal of Economic Literature, March 2011, 49(1), pp. 72-100.

Croushore, Dean and Stark, Tom. "A Real-Time Data Set for Macroeconomists." Journal of Econometrics, November 2001, 105(1), pp. 111-30.

Cukierman, Alex and Lippi, Francesco. "Endogenous Monetary Policy with Unobserved Potential Output." Journal of Economic Dynamics and Control, November 2005, 29(11), pp. 1951-83. 
de Jong, Piet. "Smoothing and Interpolation with the State-Space Model." Journal of the American Statistical Association, December 1989, 84(408), pp. 1085-8.

Dellas, Harris. "Monetary Shocks and Inflation Dynamics in a New Keynesian Model." Journal of Money, Credit and Banking, March 2006, 38(2), pp. 543-51.

Dennis, Richard. "Inferring Policy Objectives from Economic Outcomes." Oxford Bulletin of Economics and Statistics, September 2004, 66(S1), pp. 735-64.

. "The Policy Preferences of the US Federal Reserve." Journal of Applied Econometrics, January 2006, 21(1), pp. 55-77.

Dotsey, Michael and Hornstein, Andreas. "Should a Monetary Policymaker Look at Money?" Journal of Monetary Economics, April 2003, 50(3), pp. 547-79.

Ehrmann, Michael and Smets, Frank. "Uncertain Potential Output: Implications for Monetary Policy." Journal of Economic Dynamics and Control, July 2003, 27(9), pp. $1611-38$.

Erceg, Christopher J.; Henderson, Dale W. and Levin, Andrew T. "Optimal Monetary Policy with Staggered Wage and Price Contracts." Journal of Monetary Economics, October 2000, 46(2), pp. 281-313.

Estrella, Arturo and Fuhrer, Jeffrey C. "Dynamic Inconsistencies: Counterfactual Implications of a Class of Rational-Expectations Models." The American Economic Review, September 2002, 92(4), pp. 1013-28.

Favero, Carlo A. and Rovelli, Riccardo. "Macroeconomic Stability and the Preferences of the Fed: A Formal Analysis, 1961-96." Journal of Money, Credit and Banking, August 2003, 35(4), pp. 545-56.

Friedman, Milton. "The Role of Monetary Policy." The American Economic Review, March 1968, 58(1), pp. 1-17.

Fuhrer, Jeffrey C. "The (Un)Importance of Forward-Looking Behavior in Price Specifications." Journal of Money, Credit and Banking, August 1997, 29(3), pp. 338-50.

Givens, Gregory E. "Estimating Central Bank Preferences under Commitment and Discretion." forthcoming in the Journal of Money, Credit and Banking, May 2012.

Givens, Gregory E. and Salemi, Michael K. "Generalized Method of Moments and Inverse Control." Journal of Economic Dynamics and Control, October 2008, 32(10), pp. 3113-47.

Harvey, Andrew C. Forecasting, Structural Time Series Models and the Kalman Filter. Cambridge, UK: Cambridge University Press, 1989. 
Ilbas, Pelin. "Revealing the Preferences of the US Federal Reserve." Journal of Applied Econometrics, April/May 2012, 27(3), pp. 440-73.

Ingram, Beth Fisher; Kocherlakota, Narayana R. and Savin, N. E. "Explaining Business Cycles: A Multiple-Shock Approach." Journal of Monetary Economics, December 1994, 34(3), pp. 415-28.

Kiley, Michael T. "A Quantitative Comparison of Sticky-Price and Sticky-Information Models of Price Setting." Journal of Money, Credit and Banking, February 2007, 39(S1), pp. 101-25.

Kozicki, Sharon. "How Do Data Revisions Affect the Evaluation and Conduct of Monetary Policy?" Economic Review, Federal Reserve Bank of Kansas City, 2004, Q I, pp. 5-38.

Kuttner, Kenneth N. "Estimating Potential Output as a Latent Variable." Journal of Business and Economic Statistics, July 1994, 12(3), pp. 361-8.

LeRoy, Stephen F. and Waud, Roger N. "Applications of the Kalman Filter in ShortRun Monetary Control." International Economic Review, February 1977, 18(1), pp. 195207.

Lindé, Jesper. "Estimating New-Keynesian Phillips Curves: A Full Information Maximum Likelihood Approach." Journal of Monetary Economics, September 2005, 52(6), pp. 113549.

Lippi, Francesco and Neri, Stefano. "Information Variables for Monetary Policy in an Estimated Structural Model of the Euro Area." Journal of Monetary Economics, May 2007, 54(4), pp. 1256-70.

Lubik, Thomas A. and Schorfheide, Frank. "Testing for Indeterminacy: An Application to U.S. Monetary Policy." The American Economic Review, March 2004, 94(1), pp. 190217.

Mishkin, Frederic S. "Monetary Policy and the Dual Mandate." Speech at Bridgewater College, Bridgewater, Virginia, April 2007.

Neri, Stefano and Ropele, Tiziano. "Imperfect Information, Real-Time Data and Monetary Policy in the Euro Area." forthcoming in The Economic Journal, November 2011.

Orphanides, Athanasios. "Monetary Policy Rules Based on Real-Time Data." The American Economic Review, September 2001, 91(4), pp. 964-85.

. "Monetary Policy Rules and the Great Inflation." American Economic Review Papers and Proceedings, May 2002, 92(2), pp. 115-20. 
. "Monetary Policy Evaluation with Noisy Information." Journal of Monetary Economics, April 2003, 50(3), pp. 605-31.

- "Monetary Policy Rules, Macroeconomic Stability, and Inflation: A View from the Trenches." Journal of Money, Credit and Banking, April 2004, 36(2), pp. 151-75.

Orphanides, Athanasios and van Norden, Simon. "The Unreliability of Output-Gap Estimates in Real Time." The Review of Economics and Statistics, November 2002, 84(4), pp. 569-83.

Ozlale, Umit. "Price Stability vs. Output Stability: Tales of Federal Reserve Administrations." Journal of Economic Dynamics and Control, July 2003, 27(9), pp. 1595-610.

Pearlman, Joseph; Currie, David and Levine, Paul. "Rational Expectations Models with Partial Information." Economic Modelling, April 1986, 3(2), pp. 90-105.

Phelps, Edmund S. "Money-Wage Dynamics and Labor-Market Equilibrium." Journal of Political Economy, July/August 1968, 76(4), pp. 678-711.

Rotemberg, Julio J. and Woodford, Michael. "An Optimization-Based Econometric Framework for the Evaluation of Monetary Policy," in Ben S. Bernanke and Julio J. Rotemberg, eds., NBER Macroeconomics Annual. Cambridge, MA: MIT Press, 1997, pp. 297-346.

Rudebusch, Glenn D. "Is the Fed Too Timid? Monetary Policy in an Uncertain World." The Review of Economics and Statistics, May 2001, 83(2). pp. 203-17.

- "Assessing Nominal Income Rules for Monetary Policy with Model and Data Uncertainty." The Economic Journal, April 2002, 112(479), pp. 402-32.

Salemi, Michael K. "Revealed Preference of the Federal Reserve: Using Inverse-Control Theory to Interpret the Policy Equation of a Vector Autoregression." Journal of Business and Economic Statistics, October 1995, 13(4), pp. 419-33.

. "Econometric Policy Evaluation and Inverse Control," Journal of Money, Credit and Banking, October 2006, 38(7), pp. 1737-64.

Schwarz, Gideon. "Estimating the Dimension of a Model." The Annals of Statistics, March 1978, 6(2), pp. 461-4.

Söderlind, Paul. "Solution and Estimation of RE Macromodels With Optimal Policy." European Economic Review, April 1999, 43(4-6), pp. 813-23.

Söderström, Ulf; Söderlind, Paul and Vredin, Anders. "New-Keynesian Models and Monetary Policy: A Reexamination of the Stylized Facts." The Scandinavian Journal of Economics, September 2005, 107(3), pp. 521-46. 
Staiger, Douglas; Stock, James H. and Watson, Mark W. "Prices, Wages and the U.S. NAIRU in the 1990s." NBER Working Paper No. 8320, June 2001.

Svensson, Lars E.O. "Inflation Forecast Targeting: Implementing and Monitoring Inflation Targets." European Economic Review, June 1997, 41(6), pp. 1111-46.

Svensson, Lars E.O. and Woodford, Michael. "Indicator Variables for Optimal Policy." Journal of Monetary Economics, April 2003, 50(3), pp. 691-720.

Taylor, John B. "Discretion Versus Policy Rules in Practice." Carnegie-Rochester Conference Series on Public Policy, December 1993, 39, pp. 195-214.

White, Halbert. "Maximum Likelihood Estimation of Misspecified Models." Econometrica, January 1982, 50(1), pp. 1-25.

Woodford, Michael. Interest and Prices: Foundations of a Theory of Monetary Policy. Princeton and Oxford: Princeton University Press, 2003. 


\section{Appendix A. The Partial Information Model}

This appendix provides a comprehensive derivation of the empirical state-space model introduced in section 4 of the paper. For the sake of clarity and completeness, we begin by restating the structural equations of the new-Keynesian model.

$$
\begin{aligned}
y_{t} & =\phi y_{t+1 \mid t-1}+(1-\phi)\left[\beta y_{t-1}+(1-\beta) y_{t-2}\right]-\sigma\left(i_{t-1}-\pi_{t \mid t-1}\right)+\varepsilon_{y, t}, \\
\pi_{t} & =\alpha \pi_{t+1 \mid t-1}+(1-\alpha) \pi_{t-1}+\kappa\left(y_{t-1}-y_{t-1}^{n}\right)+\varepsilon_{\pi, t}, \\
y_{t}^{n} & =\theta y_{t-1}^{n}+\varepsilon_{n, t}+\eta_{y} \varepsilon_{y, t}, \\
u_{t}-u_{t}^{n} & =-\chi\left(y_{t}-y_{t}^{n}\right), \\
\mathcal{L}_{t} & =E\left[(1-\delta) \sum_{j=0}^{\infty} \delta^{j}\left\{\pi_{t+j}^{2}+\lambda_{y}\left(y_{t+j}-y_{t+j}^{n}\right)^{2}+\lambda_{i}\left(i_{t+j}-i_{t+j-1}\right)^{2}\right\} \mid \Omega_{t}\right], \\
\Delta y_{t}^{o} & =\Delta y_{t}+v_{g, t} \\
\pi_{t}^{o} & =\pi_{t}+v_{p, t}, \\
v_{g, t} & =\rho_{g} v_{g, t-1}+\varepsilon_{g, t} \\
v_{p, t} & =\rho_{p} v_{p, t-1}+\varepsilon_{p, t}, \\
\Delta u_{t} & =-\chi\left(y_{t}-y_{t}^{n}\right)+\chi\left(y_{t-1}-y_{t-1}^{n}\right)+\varepsilon_{u, t} .
\end{aligned}
$$

In Eqs. (A.1) - (A.10), $y_{t}$ and $y_{t}^{n}$ are real and natural output, $u_{t}$ and $u_{t}^{n}$ are the actual and natural rates of unemployment, $i_{t}$ is the one-period nominal interest rate, $\pi_{t}$ is the inflation rate, $\varepsilon_{y, t}$ is a demand shock, $\varepsilon_{\pi, t}$ is a "cost-push" shock, $\varepsilon_{n, t}$ is a productivity shock, $\varepsilon_{u, t}$ is the innovation to the natural unemployment rate, $\Delta y_{t}^{o}$ and $\pi_{t}^{o}$ are noisy measures of output growth and inflation, $v_{g, t}$ and $v_{p, t}$ are the corresponding noise components, and $\varepsilon_{g, t}$ and $\varepsilon_{p, t}$ are the innovations to those components. For any variable $z_{t}, z_{\tau \mid t}$ denotes $E\left[z_{\tau} \mid \Omega_{t}\right]$, the expected value of $z_{\tau}$ conditional on the private sector's date- $t$ information set $\Omega_{t}$. $\mathcal{L}_{t}$ is the quantity that the central bank minimizes.

Define $X_{t}=\left[\begin{array}{lllllllll}y_{t} & \pi_{t} & y_{t}^{n} & y_{t-1} & i_{t-1} & y_{t-1}^{n} & \varepsilon_{u, t} & v_{g, t} & v_{p, t}\end{array}\right]^{\prime}$ to be the $(9 \times 1)$ vector of date- $t$ 
predetermined variables, $x_{t}=\left[y_{t+1 \mid t} \pi_{t+1 \mid t}\right]^{\prime}$ to be the $(2 \times 1)$ vector of date- $t$ forward-looking

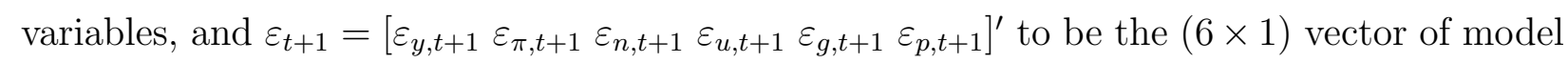
shocks with covariance matrix $\Sigma$.

Our first task is to write the structural equations as functions of $X_{t}$ and $x_{t}$. Eqs. (A.1) (A.10) can be written as

$$
\left[\begin{array}{c}
X_{t+1} \\
\Gamma x_{t+1 \mid t}
\end{array}\right]=A^{1}\left[\begin{array}{c}
X_{t} \\
x_{t}
\end{array}\right]+A^{2}\left[\begin{array}{c}
X_{t \mid t} \\
x_{t \mid t}
\end{array}\right]+B i_{t}+\left[\begin{array}{c}
N \varepsilon_{t+1} \\
\mathbf{0}_{2 \times 1}
\end{array}\right]
$$

where the $(11 \times 11)$ matrix $A^{1},(11 \times 11)$ matrix $A^{2},(11 \times 1)$ matrix $B,(2 \times 2)$ matrix $\Gamma$, $(9 \times 6)$ matrix $N$, and $(6 \times 6)$ matrix $\Sigma$ are given by

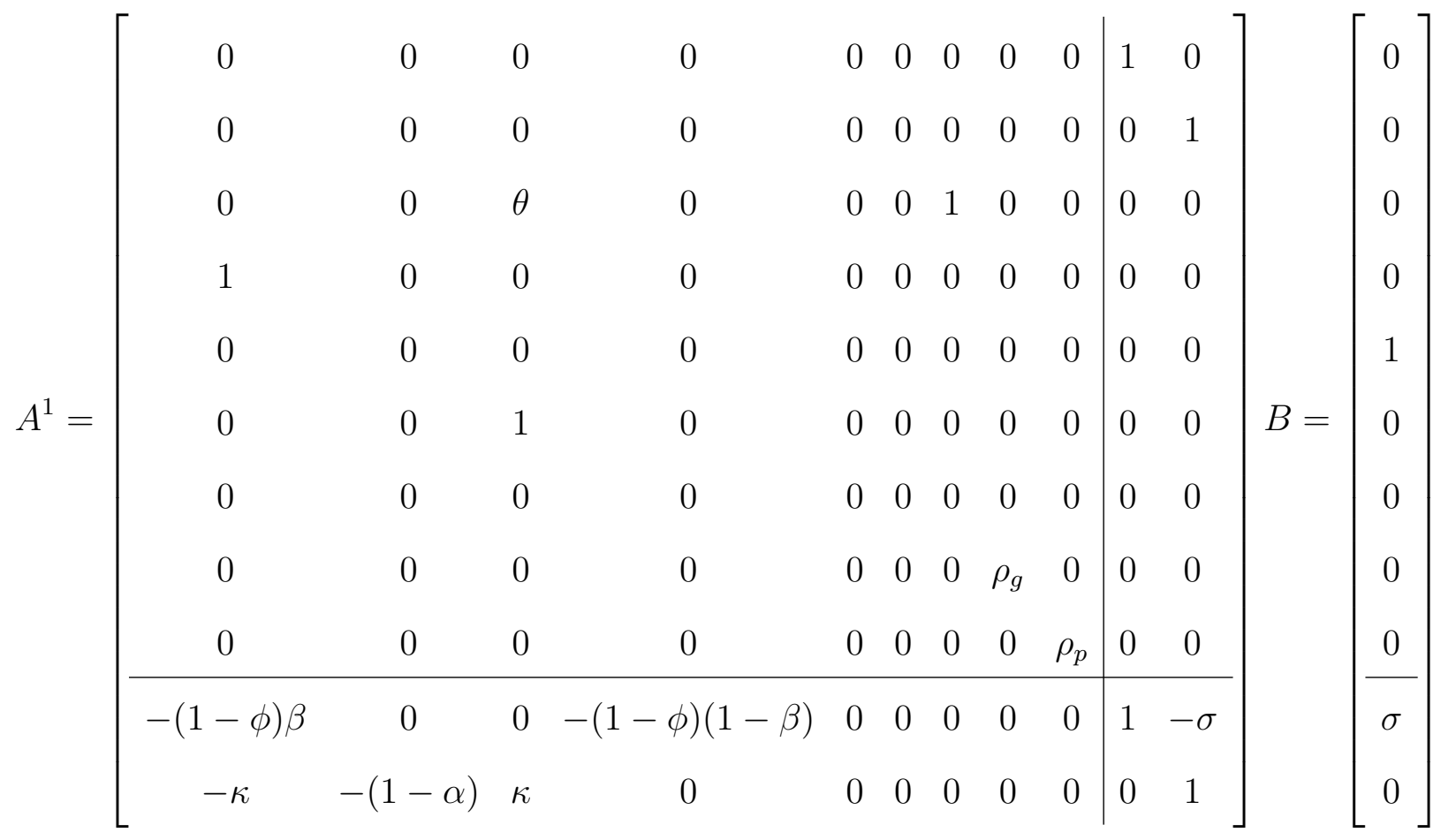

$$
\begin{aligned}
& \Gamma=\left[\begin{array}{ll}
\phi & 0 \\
0 & \alpha
\end{array}\right] \quad A^{2}=\left[\begin{array}{l|l}
\mathbf{0}_{9 \times 9} & \mathbf{0}_{9 \times 2} \\
\hline \mathbf{0}_{2 \times 9} & \mathbf{0}_{2 \times 2}
\end{array}\right]
\end{aligned}
$$




$$
N=\left[\begin{array}{cccccc}
1 & 0 & 0 & 0 & 0 & 0 \\
0 & 1 & 0 & 0 & 0 & 0 \\
\eta_{y} & 0 & 1 & 0 & 0 & 0 \\
0 & 0 & 0 & 0 & 0 & 0 \\
0 & 0 & 0 & 0 & 0 & 0 \\
0 & 0 & 0 & 0 & 0 & 0 \\
0 & 0 & 0 & 1 & 0 & 0 \\
0 & 0 & 0 & 0 & 1 & 0 \\
0 & 0 & 0 & 0 & 0 & 1
\end{array}\right] \quad \Sigma=\left[\begin{array}{cccccc}
\sigma_{y}^{2} & 0 & 0 & 0 & 0 & 0 \\
0 & \sigma_{\pi}^{2} & 0 & 0 & 0 & 0 \\
0 & 0 & \sigma_{n}^{2} & 0 & 0 & 0 \\
0 & 0 & 0 & \sigma_{u}^{2} & 0 & 0 \\
0 & 0 & 0 & 0 & \sigma_{g}^{2} & 0 \\
0 & 0 & 0 & 0 & 0 & \sigma_{p}^{2}
\end{array}\right] .
$$

The next task is to express the variables observed by the policymaker and private agents

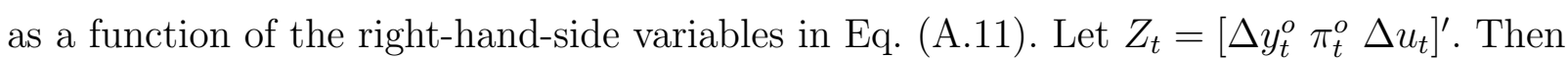

$$
Z_{t}=D X_{t}
$$

where the $(3 \times 9)$ matrix $D$ is defined as

$$
D=\left[\begin{array}{ccccccccc}
1 & 0 & 0 & -1 & 0 & 0 & 0 & 1 & 0 \\
0 & 1 & 0 & 0 & 0 & 0 & 0 & 0 & 1 \\
-\chi & 0 & \chi & \chi & 0 & -\chi & 1 & 0 & 0
\end{array}\right]
$$

The third task is to express the optimal setting of the interest rate under discretion as a function of the right-hand-side variables in Eq. (A.11). It is useful to first write the central bank loss function in terms of $X_{t}$ and $x_{t}$. Let $Y_{t}=\left[\begin{array}{ll}\pi_{t} & \left(y_{t}-y_{t}^{n}\right)\left(i_{t}-i_{t-1}\right)\end{array}\right]^{\prime}$ be the vector 
of variables appearing in the central bank's loss function. Then

$$
Y_{t}=C^{1}\left[\begin{array}{c}
X_{t} \\
x_{t}
\end{array}\right]+C^{2}\left[\begin{array}{c}
X_{t \mid t} \\
x_{t \mid t}
\end{array}\right]+C_{i} i_{t}
$$

where the $(3 \times 11)$ matrix $C^{1}$, the $(3 \times 11)$ matrix $C^{2}$, and the $(3 \times 1)$ matrix $C_{i}$ are

$$
C^{1}=\left[\begin{array}{ccccccccc|cc}
0 & 1 & 0 & 0 & 0 & 0 & 0 & 0 & 0 & 0 & 0 \\
1 & 0 & -1 & 0 & 0 & 0 & 0 & 0 & 0 & 0 & 0 \\
0 & 0 & 0 & 0 & -1 & 0 & 0 & 0 & 0 & 0 & 0
\end{array}\right] \quad C^{2}=\left[\mathbf{0}_{3 \times 9} \mid \mathbf{0}_{3 \times 2}\right] \quad C_{i}=\left[\begin{array}{c}
0 \\
0 \\
1
\end{array}\right]
$$

The loss function may then be written as

$$
\mathcal{L}_{0}=E\left[(1-\delta) \sum_{t=0}^{\infty} \delta^{t} Y_{t}^{\prime} W Y_{t} \mid \Omega_{0}\right]
$$

where $W$ is a $(3 \times 3)$ diagonal matrix with non-zero elements $\left(1, \lambda_{y}, \lambda_{i}\right)$. As explained in the body of the paper, optimal discretion implies that

$$
i_{t}=F X_{t \mid t}
$$

where $F$ is the $(1 \times 9)$ matrix that solves the Ricatti equation characterizing optimal policy.

Our fourth task is to characterize expectations under optimal policy. Private agents' estimates of the current forward-looking variables are related to their estimates of the predetermined variables according to

$$
x_{t \mid t}=G X_{t \mid t}
$$


where the $(2 \times 9)$ matrix $G$ is a fixed point of the relation

$$
G=\left(A_{22}-\Gamma G A_{12}\right)^{-1}\left[\left(\Gamma G A_{11}-A_{21}\right)+\left(\Gamma G B_{1}-B_{2}\right) F\right]
$$

and where $\left\{A_{11}, A_{12}, A_{21}, A_{22}\right\}$ are the $(9 \times 9),(9 \times 2),(2 \times 9)$, and $(2 \times 2)$ partitions of $A \equiv A^{1}+A^{2}$ conformable to $X_{t}$ and $x_{t}$. Matrices $\left\{B_{1}, B_{2}\right\}$ are the $(9 \times 1)$ and $(2 \times 1)$ partitions of $B$ likewise conformable to $X_{t}$ and $x_{t}$. It follows that under optimal discretion, the relationship between the forward-looking variables and the predetermined variables is given by

$$
x_{t}=G^{1} X_{t}+G^{2} X_{t \mid t},
$$

where the $(2 \times 9)$ matrices $G^{1}$ and $G^{2}$ satisfy $G^{1}=-\left(A_{22}^{1}\right)^{-1} A_{21}^{1}$ and $G^{2}=G-G^{1}$. It also follows that under optimal discretion, the evolution of the predetermined variables is governed by

$$
X_{t+1}=H X_{t}+J X_{t \mid t}+N \varepsilon_{t+1},
$$

where $(9 \times 9)$ matrices $H$ and $J$ satisfy $H=A_{11}^{1}+A_{12}^{1} G^{1}$ and $J=A_{12}^{1} G^{2}+A_{11}^{2}+A_{12}^{2} G+B_{1} F$.

Our fifth task is to explain how agents derive $X_{t \mid t}$. First, note that Eq. (A.12) implies that the innovation in $Z_{t}$ is a linear function of the forecast error $X_{t}-X_{t \mid t-1}$. We can therefore express the optimal prediction of $X_{t}$ in terms of the (steady-state) Kalman filter as follows

$$
\begin{aligned}
X_{t \mid t} & =X_{t \mid t-1}+K\left(Z_{t}-Z_{t \mid t-1}\right) \\
& =X_{t \mid t-1}+K D\left(X_{t}-X_{t \mid t-1}\right),
\end{aligned}
$$

where the $(9 \times 3)$ gain matrix $K$ must be determined.

To find $K$ it is helpful to reformulate the problem in terms of prediction errors so that it admits a state-space representation. Define $\tilde{X}_{t} \equiv X_{t}-X_{t \mid t-1}$ and $\tilde{Z}_{t} \equiv Z_{t}-Z_{t \mid t-1}$, and 
rewrite Eqs. (A.12) and (A.17) as

$$
\begin{aligned}
Z_{t}-Z_{t \mid t-1} & =D\left(X_{t}-X_{t \mid t-1}\right) \\
\tilde{Z}_{t} & =D \tilde{X}_{t}
\end{aligned}
$$

and

$$
\begin{aligned}
X_{t+1}-X_{t+1 \mid t} & =H X_{t}+J X_{t \mid t}+N \varepsilon_{t+1}-H X_{t \mid t}-J X_{t \mid t} \\
& =H\left(X_{t}-X_{t \mid t}\right)+N \varepsilon_{t+1} \\
& =H\left(X_{t}-X_{t \mid t-1}-K D\left(X_{t}-X_{t \mid t-1}\right)\right)+N \varepsilon_{t+1} \\
& =H(I-K D)\left(X_{t}-X_{t \mid t-1}\right)+N \varepsilon_{t+1} \\
\tilde{X}_{t+1} & =T \tilde{X}_{t}+N \varepsilon_{t+1},
\end{aligned}
$$

where we have made use of Eq. (A.18) and defined $T=H(I-K D)$.

Eqs. (A.20) and (A.19) are the state and measurement equations for a standard Kalmanfilter problem with $\tilde{X}_{t}$ as the unobserved variable and $\tilde{Z}_{t}$ as the observed variable. It follows that the prediction equation for $\tilde{X}_{t}$ is given by the standard formula for updating a linear projection (e.g., Harvey, 1989)

$$
\tilde{X}_{t \mid t}=P D^{\prime}\left(D P D^{\prime}\right)^{-1} D \tilde{X}_{t}
$$

where we use the fact that $\tilde{X}_{t \mid t-1}=0 . P \equiv \operatorname{Cov}\left[\tilde{X}_{t}-\tilde{X}_{t \mid t-1}\right]=\operatorname{Cov}\left[\tilde{X}_{t}\right]=\operatorname{Cov}\left[X_{t}-X_{t \mid t-1}\right]$ is the $(9 \times 9)$ covariance matrix of the prediction errors for $\tilde{X}_{t}$, which are the same as the prediction errors for $X_{t}$ since $\tilde{X}_{t \mid t-1}=0$. Rewrite Eq. (A.21) in terms of $X_{t}$ and $X_{t \mid t-1}$ to obtain

$$
X_{t \mid t}=X_{t \mid t-1}+P D^{\prime}\left(D P D^{\prime}\right)^{-1} D\left(X_{t}-X_{t \mid t-1}\right) .
$$


A comparison Eqs. (A.18) and (A.22) shows that the Kalman gain matrix is

$$
K=P D^{\prime}\left(D P D^{\prime}\right)^{-1}
$$

where it remains to determine P. From Eq. (A.20) we get

$$
\begin{aligned}
\operatorname{Cov}\left[\tilde{X}_{t+1}\right] \equiv P=T P T^{\prime}+N \Sigma N^{\prime} & =H(I-K D) P(I-K D)^{\prime} H^{\prime}+N \Sigma N^{\prime} \\
& =H(P-K D P)\left(I-D^{\prime} K^{\prime}\right) H^{\prime}+N \Sigma N^{\prime} \\
& =H\left[P-P D^{\prime} K^{\prime}-K D P+K D P D^{\prime} K^{\prime}\right] H^{\prime}+N \Sigma N^{\prime} \\
& =H\left[P-P D^{\prime} K^{\prime}-K D P+P D^{\prime} K^{\prime}\right] H^{\prime}+N \Sigma N^{\prime} \\
& =H[P-K D P] H^{\prime}+N \Sigma N^{\prime} \\
P & =H\left[P-P D^{\prime}\left(D P D^{\prime}\right)^{-1} D P\right] H^{\prime}+N \Sigma N^{\prime} .
\end{aligned}
$$

Therefore, $P$ is defined as the fixed point of Eq. (A.24).

The final task is to derive the augmented state-space model that we take to the data. The transition equation for the augmented state is

$$
\mathbf{s}_{t+1}=\mathbf{M} \mathbf{s}_{t}+\mathbf{N} \varepsilon_{t+1}
$$

The $(18 \times 1)$ state vector is $\mathbf{s}_{t} \equiv\left[X_{t}^{\prime} X_{t \mid t-1}^{\prime}\right]^{\prime}$ and the $(6 \times 1)$ vector of shocks is $\varepsilon_{t+1}=$ $\left[\begin{array}{llllll}\varepsilon_{y, t+1} & \varepsilon_{\pi, t+1} & \varepsilon_{n, t+1} & \varepsilon_{u, t+1} & \varepsilon_{g, t+1} & \varepsilon_{p, t+1}\end{array}\right]^{\prime}$. The $(18 \times 18)$ and $(18 \times 6)$ matrices $\mathbf{M}$ and $\mathbf{N}$ are

$$
\mathbf{M}=\left[\begin{array}{cc}
H+J K D & J(I-K D) \\
(H+J) K D & (H+J)(I-K D)
\end{array}\right] \quad \mathbf{N}=\left[\begin{array}{c}
N \\
\mathbf{0}_{9 \times 6}
\end{array}\right]
$$


The measurement equation is given by

$$
\mathbf{y}_{t}=\mathbf{T} \mathbf{s}_{t}+\mathbf{u}_{t}
$$

where $\mathbf{y}_{t} \equiv\left[\begin{array}{llll}Z_{t}^{\prime} & i_{t} \Delta y_{t} & \pi_{t}\end{array}\right]^{\prime}$ and $\mathbf{u}_{t} \equiv\left[\begin{array}{llllll}0 & 0 & 0 & u_{i, t} & 0 & 0\end{array}\right]^{\prime}$. Let $d_{t} \equiv\left[\begin{array}{ll}i_{t} \Delta y_{t} & \pi_{t}\end{array}\right]^{\prime}$. Then

$$
\begin{aligned}
d_{t} & =S X_{t}+S_{i} i_{t}+\left[\begin{array}{lll}
u_{i, t} & 0 & 0
\end{array}\right]^{\prime} \\
& =S X_{t}+S_{i} F\left(X_{t \mid t-1}+K D\left(X_{t}-X_{t \mid t-1}\right)\right)+\left[\begin{array}{lll}
u_{i, t} & 0 & 0
\end{array}\right]^{\prime},
\end{aligned}
$$

where the $(3 \times 9)$ and $(3 \times 1)$ matrices $S$ and $S_{i}$ are given by

$$
S=\left[\begin{array}{ccccccccc}
0 & 0 & 0 & 0 & 0 & 0 & 0 & 0 & 0 \\
1 & 0 & 0 & -1 & 0 & 0 & 0 & 0 & 0 \\
0 & 1 & 0 & 0 & 0 & 0 & 0 & 0 & 0
\end{array}\right] \quad S_{i}=\left[\begin{array}{l}
1 \\
0 \\
0
\end{array}\right]
$$

Stacking Eqs. (A.12) and (A.27) yields Eq. (A.26) with $(6 \times 18)$ matrix T defined as

$$
\mathbf{T}=\left[\begin{array}{cc}
D & \mathbf{0}_{3 \times 9} \\
S+S_{i} F K D & S_{i} F(I-K D)
\end{array}\right]
$$

\section{Appendix B. The Complete Information Model}

Under complete information agents perfectly observe all of the predetermined variables comprising $X_{t}$ each period. These include the true values of measured quantities such as output and inflation in addition to the purely theoretical concepts like the natural rates of output and unemployment. The aggregate behavioral relationships and the central bank's loss function represented by Eqs. (A.1) - (A.5) are exactly the same as in the partial information model. To characterize the dynamics of the model under complete information, fix the matrix $D$ in Eq. 
(A.12) equal to the identity matrix and recompute the equilibrium laws of motion given by Eqs. (A.14) - (A.18). First, note that the steady-state gain matrix $K=P D^{\prime}\left(D P D^{\prime}\right)^{-1}=I$ whenever $D=I$. It immediately follows from Eq. (A.18) that $X_{t \mid t}=X_{t}$. Replacing the optimal forecast of the predetermined state vector with its actual value in Eqs. (A.14), (A.16), and (A.17) yields the following recursive equilibrium:

$$
\begin{aligned}
i_{t} & =F X_{t} \\
x_{t} & =G X_{t} \\
X_{t+1} & =(H+J) X_{t}+N \varepsilon_{t+1},
\end{aligned}
$$

where $G=G^{1}+G^{2}$ and $H+J=A_{11}+A_{12} G+B_{1} F$. Of course, it is not surprising that the optimal strategies embodied by $F, G$, and $H+J$ are the same as the ones implied by partial information given that the model satisfies the certainty equivalence principle.

It is straightforward to express the equilibrium under complete information in state-space form so that the parameters can be estimated using maximum likelihood. Since agents' beliefs about economic conditions are always correct, there is no need to augment the state vector with efficient forecasts of the predetermined variables as in Eq. (A.25). It follows that the transition equation is simply given by Eq. (B.3).

The measurement equation links the econometrician's observed variables in period $t$ to the state $X_{t}$. As explained in section 4.1 of the paper, the set of observables relevant for estimation

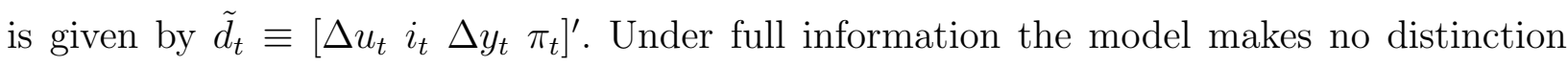
between the true values of output growth and inflation and the observable concepts that agents acquire in real time, so the measurement shocks $v_{g, t}$ and $v_{p, t}$ appearing in Eqs. (A.6) and (A.7) equal zero in every period. As a result, we discard the real-time data on these variables and estimate the model using only the final published data described in section 4 . 
Specifically, the measurement equation takes the form

$$
\begin{aligned}
\tilde{d}_{t} & =\tilde{S} X_{t}+\tilde{S}_{i} i_{t}+\left[\begin{array}{llll}
0 & u_{i, t} & 0 & 0
\end{array}\right]^{\prime} \\
& =\left(\tilde{S}+\tilde{S}_{i} F\right) X_{t}+\left[\begin{array}{llll}
0 & u_{i, t} & 0 & 0
\end{array}\right]^{\prime},
\end{aligned}
$$

where

$$
\tilde{S}=\left[\begin{array}{ccccccccc}
-\chi & 0 & \chi & \chi & 0 & -\chi & 1 & 0 & 0 \\
0 & 0 & 0 & 0 & 0 & 0 & 0 & 0 & 0 \\
1 & 0 & 0 & -1 & 0 & 0 & 0 & 0 & 0 \\
0 & 1 & 0 & 0 & 0 & 0 & 0 & 0 & 0
\end{array}\right] \quad \tilde{S}_{i}=\left[\begin{array}{l}
0 \\
1 \\
0 \\
0
\end{array}\right]
$$

The system given by Eqs. (B.3) and (B.4) can then be used to evaluate the log-likelihood function using standard Kalman filtering techniques.

\section{Appendix C. Forward-Looking Indicators}

In the partial information model presented in section 2 , all of the indicator variables are predetermined. The standard Kalman filter can therefore be used to forecast the state as illustrated in appendix A. When there are forward-looking indicators, however, agents face a simultaneity problem that makes the standard Kalman filter inapplicable. In this case the indicators are determined, in part, by expectations of future endogenous variables. Simultaneity arises because these expectations depend on an estimate of the current state, and that estimate in turn depends on observations of the forward-looking indicators. Pearlman et al. (1986), and more recently Svensson and Woodford (2003), demonstrate how the signalextraction problem can be recast as one involving only predetermined indicators. They go on to show that the updating equations take the form of a modified Kalman filter capable of handling the kind of simultaneity issue described above.

In this appendix we present estimates from a variant of the benchmark model in which the 
observables are forward-looking rather than predetermined. Specifically, the model replaces Eqs. (A.1) and (A.2) with IS and Phillips curves of the form

$$
\begin{aligned}
y_{t} & =\phi y_{t+1 \mid t}+(1-\phi)\left[\beta y_{t-1}+(1-\beta) y_{t-2}\right]-\sigma\left(i_{t}-\pi_{t+1 \mid t}\right)+\varepsilon_{y, t} \\
\pi_{t} & =\alpha \pi_{t+1 \mid t}+(1-\alpha) \pi_{t-1}+\kappa\left(y_{t}-y_{t}^{n}\right)+\varepsilon_{\pi, t} .
\end{aligned}
$$

The only changes appearing in Eqs. (C.1) and (C.2) are the removal of lags in the transmission mechanism and in the dating of conditional expectations. These adjustments to the timing protocols mean that current and expected future policy actions will now have a contemporaneous effect on the indicators given by $Z_{t}=\left[\Delta y_{t}^{o} \pi_{t}^{o} \Delta u_{t}\right]^{\prime}$. The rest of the aggregate relationships in the model as well as the loss function stay the same.

To write the structural model in the form of Eq. (A.11), we redefine the vector of prede-

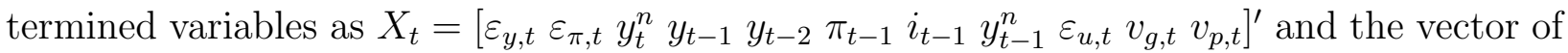
forward-looking variables as $x_{t}=\left[y_{t} \pi_{t}\right]^{\prime}$. The indicators are then linked to the state by

$$
Z_{t}=\left[D_{1} \mid D_{2}\right]\left[\begin{array}{l}
X_{t} \\
x_{t}
\end{array}\right]
$$

where $D_{1}$ and $D_{2}$ are submatrices conformable to $X_{t}$ and $x_{t}$. We use the algorithms provided by Svensson and Woodford (2003) to compute the equilibrium under optimal discretion. The solution procedure yields a policy rule expressing the interest rate as a function of $X_{t \mid t}$, laws of motion for $X_{t}, x_{t}$, and $Z_{t}$, and a forecasting equation for $X_{t \mid t}$ describing how agents update their beliefs about the predetermined state variables. The entire system is then mapped into state-space form in a manner similar to that described in appendix A, and the parameters are estimated by maximum likelihood. Like the analysis of section 5.1, we compare estimates of the model with partial information to those from a version in which agents have complete information about the state. The results appear in Table 6 . 
With a few exceptions, estimates of the model containing forward-looking indicators are close to those of the benchmark model featuring only backward-looking indicators. Estimates of the demand shock $\sigma_{y}$, for example, are smaller in the case of forward-looking indicators under both partial and complete information. The Phillips curve parameters are also somewhat different but only under partial information. With forward-looking indicators, the point estimate of $\alpha$ becomes smaller while that of $\kappa$ becomes larger, although neither is statistically significant. Importantly, the presence of forward-looking indicators does not greatly affect inferences concerning the weight on output gap stability. The estimate of $\lambda_{y}$ is 0.32 with a standard error of 0.11 under partial information, but under complete information the estimate is 0.42 with a standard error of 0.35 . Thus only in the case of partial information is $\lambda_{y}$ significantly different from zero. Regarding the weight on interest rate smoothing, the point estimate of $\lambda_{i}$ is still insignificant under complete information but is now large and significant under partial information. Finally, log likelihood in the partial information model with forward-looking indicators is -725.30 compared to -671.25 in the benchmark model with backward-looking indicators. Although it does not constitute a formal hypothesis test (since the models are non-nested), the fact that log likelihood is higher in the benchmark model suggests that it is more congruent with the observed data.

\section{Appendix D. An Estimate of the Gain Matrix}

In this appendix we clarify how the indicator variables are used by private agents and the central bank in revising their forecasts of the state. This information is provided by estimates of the Kalman gain matrix $K$. Recall that inferences about the value of $X_{t}$ are updated on the basis of new observations on $Z_{t}$ according to $X_{t \mid t}=X_{t \mid t-1}+K\left(Z_{t}-Z_{t \mid t-1}\right)$. Thus the $(i, j)$ element of $K$ is the weight placed on innovations to the $j^{\text {th }}$ indicator on forecasts of the 
$i^{\text {th }}$ state variable. Given the partial information estimates in Table 1, the gain matrix is

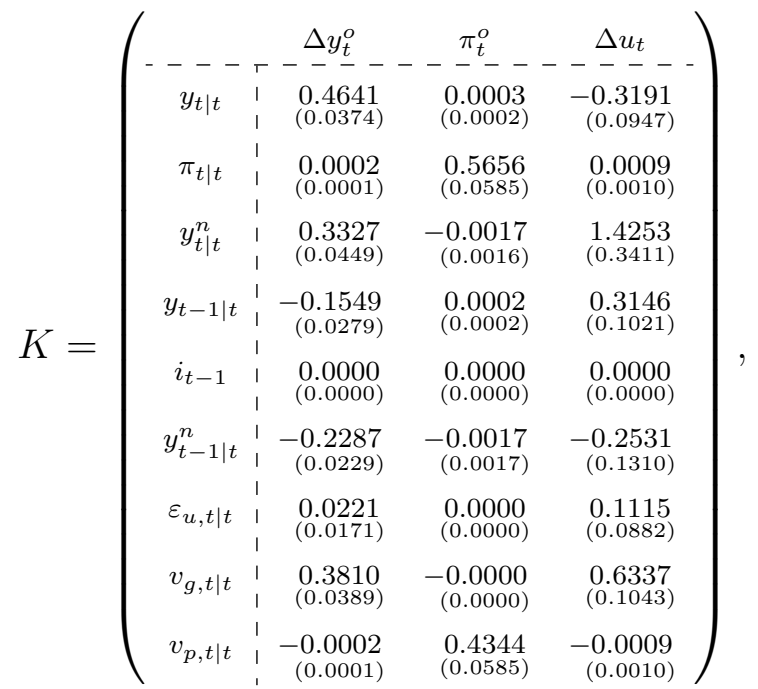

where standard errors (in parentheses) are found using the delta method.

Among the findings revealed by our estimate of $K$, one that stands out is the asymmetric effect changes in the unemployment rate have on real-time estimates of the output gap and inflation. A unit innovation to $\Delta u_{t}$ evidently causes agents to revise down their forecast of the output gap (i.e., $\left.y_{t \mid t}-y_{t \mid t}^{n}\right)$ by 1.7444 percentage points $(-0.3191-1.4253=-1.7444)$ but revise up their forecast of inflation $\pi_{t \mid t}$ by only 0.0009 percentage points. The reason why agents rely heavily on $\Delta u_{t}$ in forming estimates of the output gap but very little in estimating inflation is because the signal-to-noise ratio implied by the structural model is considerably higher in the former. This is a result of the strong contemporaneous linkage between unemployment and the output gap established by Okun's Law. In the partial information model the estimated value of the Okun coefficient $\chi$ is 0.3843 . The relationship with inflation, however, is far weaker since nominal factors only affect unemployment indirectly by shifting output via the real interest rate. The estimate of the slope coefficient $\sigma$ in the IS equation is 0.0009. It follows that inflation-induced changes in the real interest rate will have rather small effects on output and hence the unemployment rate. 
Table 1

Parameter Estimates

\begin{tabular}{|c|c|c|c|c|c|}
\hline Model & Parameter & Partial & Complete & Partial & Complete \\
\hline Parameter & Description & Information & Information & Information & Information \\
\hline$\sigma_{y}$ & demand shock & $\begin{array}{l}0.6831 \\
(0.0539)\end{array}$ & $\begin{array}{l}0.7302 \\
(0.0608)\end{array}$ & $\begin{array}{l}0.6718 \\
(0.0601)\end{array}$ & $\begin{array}{r}0.7299 \\
(0.0624)\end{array}$ \\
\hline$\sigma_{\pi}$ & cost-push shock & $\begin{array}{l}0.9367 \\
(0.1083)\end{array}$ & $\begin{array}{l}1.0424 \\
(0.1269)\end{array}$ & $\begin{array}{l}0.9455 \\
(0.1037)\end{array}$ & $\begin{array}{l}1.0406 \\
(0.1248)\end{array}$ \\
\hline$\sigma_{n}$ & natural output shock & $\begin{array}{l}0.5149 \\
(0.0702)\end{array}$ & $\begin{array}{l}0.2805 \\
(0.0381)\end{array}$ & $\begin{array}{l}0.4952 \\
(0.1471)\end{array}$ & $\begin{array}{l}0.2827 \\
(0.0574)\end{array}$ \\
\hline$\sigma_{u}$ & natural unemployment shock & $\begin{array}{l}0.0790 \\
(0.0313)\end{array}$ & $\begin{array}{l}0.1678 \\
(0.0233)\end{array}$ & $\begin{array}{l}0.0308 \\
(0.1251)\end{array}$ & $\begin{array}{l}0.1674 \\
(0.0212)\end{array}$ \\
\hline$\sigma_{g}$ & output growth noise & $\begin{array}{l}0.4229 \\
(0.0280)\end{array}$ & - & $\begin{array}{l}0.4428 \\
(0.0435)\end{array}$ & - \\
\hline$\sigma_{p}$ & inflation noise & $\begin{array}{l}0.8780 \\
(0.0641)\end{array}$ & - & $\begin{array}{l}0.8808 \\
(0.0664)\end{array}$ & - \\
\hline$\sigma_{i}$ & interest rate shock & $\begin{array}{l}0.8602 \\
(0.0564)\end{array}$ & $\begin{array}{l}0.6689 \\
(0.0870)\end{array}$ & $\begin{array}{l}0.8701 \\
(0.0515)\end{array}$ & $\begin{array}{l}0.6715 \\
(0.0639)\end{array}$ \\
\hline$\rho_{g}$ & serial correlation in $\sigma_{g}$ & $\begin{array}{r}-0.1076 \\
(0.0893)\end{array}$ & - & $\begin{array}{r}-0.0476 \\
(0.1441)\end{array}$ & - \\
\hline$\rho_{p}$ & serial correlation in $\sigma_{p}$ & $\begin{array}{l}0.0981 \\
(0.0902)\end{array}$ & - & $\begin{array}{l}0.1069 \\
(0.0927)\end{array}$ & - \\
\hline$\phi$ & expected future output & $\begin{array}{l}0.3610 \\
(0.0049)\end{array}$ & $\begin{array}{l}0.3770 \\
(0.0053)\end{array}$ & $\begin{array}{l}0.3493 \\
(0.0032)\end{array}$ & $\begin{array}{l}0.3775 \\
(0.0058)\end{array}$ \\
\hline$\beta$ & lagged output & $\begin{array}{l}1.4752 \\
(0.0073)\end{array}$ & $\begin{array}{l}1.4448 \\
(0.0091)\end{array}$ & $\begin{array}{l}1.4934 \\
(0.0093)\end{array}$ & $\begin{array}{l}1.4448 \\
(0.0089)\end{array}$ \\
\hline$\sigma$ & interest rate elasticity & $\begin{array}{l}0.0009 \\
(0.0003)\end{array}$ & $\begin{array}{l}0.0006 \\
(0.0004)\end{array}$ & $\begin{array}{l}0.0012 \\
(0.0006)\end{array}$ & $\begin{array}{l}0.0006 \\
(0.0003)\end{array}$ \\
\hline$\alpha$ & expected future inflation & $\begin{array}{l}0.4727 \\
(0.0240)\end{array}$ & $\begin{array}{l}0.5298 \\
(0.0168)\end{array}$ & $\begin{array}{l}0.4464 \\
(0.0662)\end{array}$ & $\begin{array}{l}0.5329 \\
(0.0061)\end{array}$ \\
\hline$\kappa$ & output gap elasticity & $\begin{array}{l}0.0032 \\
(0.0029)\end{array}$ & $\begin{array}{l}0.0015 \\
(0.0056)\end{array}$ & $\begin{array}{l}0.0110 \\
(0.0132)\end{array}$ & $\begin{array}{l}8.99 \mathrm{e}-8 \\
(2.35 \mathrm{e}-8)\end{array}$ \\
\hline$\theta$ & lagged natural output & $\begin{array}{l}0.9107 \\
(0.0116)\end{array}$ & $\begin{array}{l}0.9273 \\
(0.0155)\end{array}$ & $\begin{array}{l}0.9138 \\
(0.0097)\end{array}$ & $\begin{array}{l}0.9269 \\
(0.0192)\end{array}$ \\
\hline$\eta_{y}$ & demand shock feedback & $\begin{array}{l}0.3224 \\
(0.0798)\end{array}$ & $\begin{array}{l}0.4649 \\
(0.0711)\end{array}$ & $\begin{array}{l}0.3578 \\
(0.0933)\end{array}$ & $\begin{array}{l}0.4646 \\
(0.0705)\end{array}$ \\
\hline$\chi$ & Okun coefficient & $\begin{array}{l}0.3843 \\
(0.0327)\end{array}$ & $\begin{array}{l}0.4641 \\
(0.0583)\end{array}$ & $\begin{array}{l}0.4168 \\
(0.1239)\end{array}$ & $\begin{array}{l}0.4636 \\
(0.0639)\end{array}$ \\
\hline$\delta$ & loss discount factor & $0.99^{*}$ & $0.99^{*}$ & $0.99^{*}$ & $0.99^{*}$ \\
\hline$\lambda_{y}$ & output gap weight & $\begin{array}{l}0.2687 \\
(0.1196)\end{array}$ & $\begin{array}{l}0.1478 \\
(0.5042)\end{array}$ & $0^{*}$ & $0^{*, \dagger}$ \\
\hline$\lambda_{i}$ & interest-rate smoothing weight & $\begin{array}{r}0.7578 \\
(0.5318)\end{array}$ & $\begin{array}{r}0.1552 \\
(0.5258)\end{array}$ & $\begin{array}{r}1.8982 \\
(0.7170)\end{array}$ & $\begin{array}{r}1.03 \mathrm{e}-5 \\
(2.10 \mathrm{e}-7)\end{array}$ \\
\hline $\ln \mathcal{L}$ & log likelihood & -671.2532 & -445.1656 & -675.5590 & -445.2034 \\
\hline
\end{tabular}

Notes: The table reports maximum-likelihood estimates of Eqs. (1) - (10) under partial and complete information. Numbers in parentheses are standard errors. ${ }^{*}$ denotes a value that is imposed prior to estimation. ${ }^{\dagger}$ The restriction in this case is $\lambda_{y}=1 \mathrm{e}-5$. 
Table 2

Policy-Rule Coefficient Estimates

\begin{tabular}{|c|c|c|c|c|}
\hline \multirow[b]{2}{*}{ Coefficient } & \multicolumn{2}{|c|}{ Partial Information } & \multicolumn{2}{|c|}{ Complete Information } \\
\hline & Optimal & Unrestricted & Optimal & Unrestricted \\
\hline$\gamma_{y}$ & $\begin{array}{l}0.6784 \\
(0.0555)\end{array}$ & $\begin{array}{l}0.6641 \\
(0.0721)\end{array}$ & $\begin{array}{l}0.6385 \\
(0.0892)\end{array}$ & $\begin{array}{l}2.5171 \\
(1.1078)\end{array}$ \\
\hline$\gamma_{\pi}$ & $\begin{array}{l}0.2940 \\
(0.0315)\end{array}$ & $\begin{array}{l}0.2944 \\
(0.0509)\end{array}$ & $\begin{array}{l}0.2684 \\
(0.0471)\end{array}$ & $\begin{array}{l}0.2757 \\
(0.0902)\end{array}$ \\
\hline$\gamma_{n}$ & $\begin{array}{r}-0.1311 \\
(0.0320)\end{array}$ & $\begin{array}{r}-0.3480 \\
(0.2561)\end{array}$ & $\begin{array}{r}-0.2474 \\
(0.0756)\end{array}$ & $\begin{array}{r}-5.0534 \\
(3.5627)\end{array}$ \\
\hline$\gamma_{y y}$ & $\begin{array}{r}-0.6629 \\
(0.0526)\end{array}$ & $\begin{array}{r}-0.6374 \\
(0.0623)\end{array}$ & $\begin{array}{r}-0.5617 \\
(0.0792)\end{array}$ & $\begin{array}{r}-2.4589 \\
(1.1505)\end{array}$ \\
\hline$\gamma_{i}$ & $\begin{array}{l}0.8575 \\
(0.0167)\end{array}$ & $\begin{array}{l}0.8561 \\
(0.0219)\end{array}$ & $\begin{array}{l}0.8770 \\
(0.0239)\end{array}$ & $\begin{array}{l}0.8988 \\
(0.1672)\end{array}$ \\
\hline
\end{tabular}

Notes: The table reports maximum-likelihood estimates of policy-rule coefficients under partial and complete information. In each case the first set of estimates are the optimal coefficients implied by discretionary policy and the second are the unrestricted estimates obtained by treating the policy equation as free. Numbers in parentheses are standard errors. 
Table 3

Parameter Estimates under Optimal and Unrestricted Policy

\begin{tabular}{|c|c|c|c|c|c|}
\hline \multirow{2}{*}{$\begin{array}{l}\text { Model } \\
\text { Parameter }\end{array}$} & \multirow{2}{*}{$\begin{array}{l}\text { Parameter } \\
\text { Description }\end{array}$} & \multicolumn{2}{|c|}{ Partial Information } & \multicolumn{2}{|c|}{ Complete Information } \\
\hline & & Optimal & Unrestricted & Optimal & Unrestricted \\
\hline$\sigma_{y}$ & demand shock & $\begin{array}{l}0.6831 \\
(0.0539)\end{array}$ & $\begin{array}{l}0.6521 \\
(0.0564)\end{array}$ & $\begin{array}{l}0.7302 \\
(0.0608)\end{array}$ & $\begin{array}{l}0.6806 \\
(0.0544)\end{array}$ \\
\hline$\sigma_{\pi}$ & cost-push shock & $\begin{array}{l}0.9367 \\
(0.1083)\end{array}$ & $\begin{array}{l}0.9399 \\
(0.1103)\end{array}$ & $\begin{array}{l}1.0424 \\
(0.1269)\end{array}$ & $\begin{array}{l}1.0425 \\
(0.1235)\end{array}$ \\
\hline$\sigma_{n}$ & natural output shock & $\begin{array}{l}0.5149 \\
(0.0702)\end{array}$ & $\begin{array}{l}0.3327 \\
(0.1914)\end{array}$ & $\begin{array}{l}0.2805 \\
(0.0381)\end{array}$ & $\begin{array}{l}0.1270 \\
(0.0378)\end{array}$ \\
\hline$\sigma_{u}$ & natural unemployment shock & $\begin{array}{l}0.0790 \\
(0.0313)\end{array}$ & $\begin{array}{l}0.1446 \\
(0.0639)\end{array}$ & $\begin{array}{l}0.1678 \\
(0.0233)\end{array}$ & $\begin{array}{l}0.1832 \\
(0.0122)\end{array}$ \\
\hline$\sigma_{g}$ & output growth noise & $\begin{array}{l}0.4229 \\
(0.0280)\end{array}$ & $\begin{array}{l}0.4387 \\
(0.0300)\end{array}$ & - & - \\
\hline$\sigma_{p}$ & inflation noise & $\begin{array}{l}0.8780 \\
(0.0641)\end{array}$ & $\begin{array}{l}0.8793 \\
(0.0659)\end{array}$ & - & - \\
\hline$\sigma_{i}$ & interest rate shock & $\begin{array}{l}0.8602 \\
(0.0564)\end{array}$ & $\begin{array}{l}0.8573 \\
(0.0641)\end{array}$ & $\begin{array}{l}0.6689 \\
(0.0870)\end{array}$ & $\begin{array}{l}0.1803 \\
(0.6388)\end{array}$ \\
\hline$\rho_{g}$ & serial correlation in $\sigma_{g}$ & $\begin{array}{r}-0.1076 \\
(0.0893)\end{array}$ & $\begin{array}{r}-0.0656 \\
(0.0918)\end{array}$ & - & - \\
\hline$\rho_{p}$ & serial correlation in $\sigma_{p}$ & $\begin{array}{l}0.0981 \\
(0.0902)\end{array}$ & $\begin{array}{l}0.1007 \\
(0.0890)\end{array}$ & - & - \\
\hline$\phi$ & expected future output & $\begin{array}{l}0.3610 \\
(0.0049)\end{array}$ & $\begin{array}{l}0.3448 \\
(0.0045)\end{array}$ & $\begin{array}{l}0.3770 \\
(0.0053)\end{array}$ & $\begin{array}{l}0.4430 \\
(0.0245)\end{array}$ \\
\hline$\beta$ & lagged output & $\begin{array}{l}1.4752 \\
(0.0073)\end{array}$ & $\begin{array}{l}1.5089 \\
(0.0110)\end{array}$ & $\begin{array}{l}1.4448 \\
(0.0091)\end{array}$ & $\begin{array}{l}1.2397 \\
(0.0827)\end{array}$ \\
\hline$\sigma$ & interest rate elasticity & $\begin{array}{l}0.0009 \\
(0.0003)\end{array}$ & $\begin{array}{l}0.0007 \\
(0.0005)\end{array}$ & $\begin{array}{l}0.0006 \\
(0.0004)\end{array}$ & $\begin{array}{l}0.0013 \\
(0.0029)\end{array}$ \\
\hline$\alpha$ & expected future inflation & $\begin{array}{l}0.4727 \\
(0.0240)\end{array}$ & $\begin{array}{l}0.4630 \\
(0.0301)\end{array}$ & $\begin{array}{l}0.5298 \\
(0.0168)\end{array}$ & $\begin{array}{l}0.5383 \\
(0.0219)\end{array}$ \\
\hline$\kappa$ & output gap elasticity & $\begin{array}{l}0.0032 \\
(0.0029)\end{array}$ & $\begin{array}{l}0.0033 \\
(0.0036)\end{array}$ & $\begin{array}{l}0.0015 \\
(0.0056)\end{array}$ & $\begin{array}{l}1.61 \mathrm{e}-9 \\
(0.0005)\end{array}$ \\
\hline$\theta$ & lagged natural output & $\begin{array}{l}0.9107 \\
(0.0116)\end{array}$ & $\begin{array}{l}0.9278 \\
(0.0233)\end{array}$ & $\begin{array}{l}0.9273 \\
(0.0155)\end{array}$ & $\begin{array}{l}0.2774 \\
(0.2032)\end{array}$ \\
\hline$\eta_{y}$ & demand shock feedback & $\begin{array}{l}0.3224 \\
(0.0798)\end{array}$ & $\begin{array}{l}0.4175 \\
(0.0875)\end{array}$ & $\begin{array}{l}0.4649 \\
(0.0711)\end{array}$ & $\begin{array}{l}0.4015 \\
(0.0780)\end{array}$ \\
\hline$\chi$ & Okun coefficient & $\begin{array}{l}0.3843 \\
(0.0327)\end{array}$ & $\begin{array}{l}0.4302 \\
(0.0506)\end{array}$ & $\begin{array}{l}0.4641 \\
(0.0583)\end{array}$ & $\begin{array}{l}0.4280 \\
(0.0339)\end{array}$ \\
\hline$\delta$ & loss discount factor & $0.99^{*}$ & - & $0.99^{*}$ & - \\
\hline$\lambda_{y}$ & output gap weight & $\begin{array}{l}0.2687 \\
(0.1196)\end{array}$ & - & $\begin{array}{l}0.1478 \\
(0.5042)\end{array}$ & - \\
\hline$\lambda_{i}$ & interest-rate smoothing weight & $\begin{array}{r}0.7578 \\
(0.5318)\end{array}$ & - & $\begin{array}{r}0.1552 \\
(0.5258)\end{array}$ & - \\
\hline $\ln \mathcal{L}$ & log likelihood & -671.2532 & -665.5937 & -445.1656 & -406.8995 \\
\hline$B I C$ & Bayesian information criterion & -716.9690 & -718.5277 & -481.2570 & -450.2092 \\
\hline $\mathcal{M}$ & pseudo-posterior odds & 0.8262 & 0.1738 & 0.0000 & 1.0000 \\
\hline
\end{tabular}

Notes: The table reports maximum-likelihood estimates of Eqs. (1) - (10) under partial and complete information. In each case the first set of estimates is obtained under discretion and the second set is obtained under the unrestricted policy. Numbers in parentheses are standard errors. ${ }^{*}$ denotes a value that is imposed prior to estimation. 
Table 4

Summary Statistics: 1979:Q3 - 2010:Q1

\begin{tabular}{lrrccc}
\hline \hline Variable & Mean & SD & Min & Max & AR \\
\hline$\hat{q}_{t}$ & -1.06 & 4.49 & -13.64 & 5.50 & 0.98 \\
$\hat{q}_{t \mid t}$ & -1.84 & 4.19 & -13.68 & 3.99 & 0.99 \\
$\hat{q}_{t \mid t}-\hat{q}_{t}$ & -0.78 & 0.42 & -1.59 & 0.45 & 0.93 \\
$\hat{\pi}_{t}$ & 0.00 & 2.03 & -4.25 & 8.09 & 0.84 \\
$\hat{\pi}_{t \mid t}$ & 0.01 & 1.89 & -2.27 & 6.62 & 0.92 \\
$\hat{\pi}_{t \mid t}-\hat{\pi}_{t}$ & 0.01 & 0.72 & -2.07 & 2.52 & 0.28 \\
\hline \hline
\end{tabular}

Notes: The sample consists of 123 quarterly estimates obtained from the Kalman smoother. $\hat{q}_{t}$ and $\hat{q}_{t \mid t}$ are estimates of the actual and perceived values of the output gap (i.e., $y_{t}-y_{t}^{n}$ ), while $\hat{\pi}_{t}$ and $\hat{\pi}_{t \mid t}$ are estimates of the actual and perceived values of inflation. The statistics shown for each variable are: Mean, the mean; SD, the standard deviation; Min and Max, the minimum and maximum values; and AR, the first-order autocorrelation coefficient. 
Table 5

Variance Decompositions

\begin{tabular}{lrrrrrr}
\hline \hline & \multicolumn{3}{c}{$q_{t \mid t}-q_{t}$} & \multicolumn{3}{c}{$\pi_{t \mid t}-\pi_{t}$} \\
Forecast Horizon & 1 -Year & 3-Year & 10-Year & 1-Year & 3 -Year & 10 -Year \\
\hline demand shock & 4.8445 & 2.2682 & 2.1647 & 0.0000 & 0.0000 & 0.0000 \\
& $(2.2782)$ & $(0.9873)$ & $(1.1688)$ & $(0.0000)$ & $(0.0000)$ & $(0.0000)$ \\
cost-push shock & 0.0082 & 0.0090 & 0.0091 & 40.1764 & 40.1763 & 40.1762 \\
& $(0.0167)$ & $(0.0184)$ & $(0.0185)$ & $(5.3094)$ & $(5.3093)$ & $(5.3092)$ \\
natural output shock & 54.1239 & 59.3571 & 62.0603 & 0.0000 & 0.0002 & 0.0004 \\
& $(6.0727)$ & $(5.6982)$ & $(4.7606)$ & $(0.0001)$ & $(0.0004)$ & $(0.0008)$ \\
natural unemployment shock & 35.7956 & 35.5043 & 34.1008 & 0.0000 & 0.0001 & 0.0002 \\
& $(6.4756)$ & $(6.5361)$ & $(6.4918)$ & $(0.0000)$ & $(0.0002)$ & $(0.0004)$ \\
output growth noise & 5.2242 & 2.8581 & 1.6625 & 0.0000 & 0.0000 & 0.0000 \\
& $(1.9397)$ & $(1.2108)$ & $(1.0021)$ & $(0.0000)$ & $(0.0000)$ & $(0.0000)$ \\
inflation noise & 0.0036 & 0.0029 & 0.0026 & 59.8235 & 59.8234 & 59.8232 \\
& $(0.0073)$ & $(0.0059)$ & $(0.0053)$ & $(5.3095)$ & $(5.3096)$ & $(5.3098)$ \\
\hline \hline
\end{tabular}

Notes: The table reports the percentage of the variances of output gap misperceptions $\left(q_{t \mid t}-q_{t}\right)$ and inflation misperceptions $\left(\pi_{t \mid t}-\pi_{t}\right)$ attributed to each shock. Error variances are computed at a 1-year, 3-year, and 10-year forecast horizon for both variables. Numbers in parentheses are standard errors obtained using the delta method. 
Table 6

Forward-Looking Indicators

\begin{tabular}{|c|c|c|c|c|c|}
\hline \multirow{2}{*}{$\begin{array}{l}\text { Model } \\
\text { Parameter }\end{array}$} & \multirow{2}{*}{$\begin{array}{l}\text { Parameter } \\
\text { Description }\end{array}$} & \multicolumn{2}{|c|}{ Forward-Looking Indicators } & \multicolumn{2}{|c|}{ Predetermined Indicators } \\
\hline & & Partial & Complete & Partial & Complete \\
\hline$\sigma_{y}$ & demand shock & $\begin{array}{l}0.4632 \\
(0.0309)\end{array}$ & $\begin{array}{r}0.2730 \\
(0.0225)\end{array}$ & $\begin{array}{l}0.6831 \\
(0.0539)\end{array}$ & $\begin{array}{r}0.7302 \\
(0.0608)\end{array}$ \\
\hline$\sigma_{\pi}$ & cost-push shock & $\begin{array}{l}0.8728 \\
(0.2862)\end{array}$ & $\begin{array}{l}0.5642 \\
(0.0730)\end{array}$ & $\begin{array}{l}0.9367 \\
(0.1083)\end{array}$ & $\begin{array}{l}1.0424 \\
(0.1269)\end{array}$ \\
\hline$\sigma_{n}$ & natural output shock & $\begin{array}{l}0.5491 \\
(0.0672)\end{array}$ & $\begin{array}{l}0.2918 \\
(0.0448)\end{array}$ & $\begin{array}{l}0.5149 \\
(0.0702)\end{array}$ & $\begin{array}{l}0.2805 \\
(0.0381)\end{array}$ \\
\hline$\sigma_{u}$ & natural unemployment shock & $\begin{array}{l}0.0746 \\
(0.0288)\end{array}$ & $\begin{array}{l}0.1670 \\
(0.0245)\end{array}$ & $\begin{array}{l}0.0790 \\
(0.0313)\end{array}$ & $\begin{array}{l}0.1678 \\
(0.0233)\end{array}$ \\
\hline$\sigma_{g}$ & output growth noise & $\begin{array}{l}0.4752 \\
(0.0315)\end{array}$ & - & $\begin{array}{l}0.4229 \\
(0.0280)\end{array}$ & - \\
\hline$\sigma_{p}$ & inflation noise & $\begin{array}{l}0.8809 \\
(0.0921)\end{array}$ & - & $\begin{array}{l}0.8780 \\
(0.0641)\end{array}$ & - \\
\hline$\sigma_{i}$ & interest rate shock & $\begin{array}{l}0.8721 \\
(0.0596)\end{array}$ & $\begin{array}{l}0.6763 \\
(0.0873)\end{array}$ & $\begin{array}{l}0.8602 \\
(0.0564)\end{array}$ & $\begin{array}{l}0.6689 \\
(0.0870)\end{array}$ \\
\hline$\rho_{g}$ & serial correlation in $\sigma_{g}$ & $\begin{array}{l}0.0094 \\
(0.0940)\end{array}$ & - & $\begin{array}{r}-0.1076 \\
(0.0893)\end{array}$ & - \\
\hline$\rho_{p}$ & serial correlation in $\sigma_{p}$ & $\begin{array}{l}0.1200 \\
(0.1118)\end{array}$ & - & $\begin{array}{l}0.0981 \\
(0.0902)\end{array}$ & - \\
\hline$\phi$ & expected future output & $\begin{array}{l}0.3593 \\
(0.0037)\end{array}$ & $\begin{array}{l}0.3724 \\
(0.0052)\end{array}$ & $\begin{array}{l}0.3610 \\
(0.0049)\end{array}$ & $\begin{array}{l}0.3770 \\
(0.0053)\end{array}$ \\
\hline$\beta$ & lagged output & $\begin{array}{l}1.4878 \\
(0.0061)\end{array}$ & $\begin{array}{l}1.4536 \\
(0.0114)\end{array}$ & $\begin{array}{l}1.4752 \\
(0.0073)\end{array}$ & $\begin{array}{l}1.4448 \\
(0.0091)\end{array}$ \\
\hline$\sigma$ & interest rate elasticity & $\begin{array}{l}0.0012 \\
(0.0004)\end{array}$ & $\begin{array}{l}0.0006 \\
(0.0004)\end{array}$ & $\begin{array}{l}0.0009 \\
(0.0003)\end{array}$ & $\begin{array}{l}0.0006 \\
(0.0004)\end{array}$ \\
\hline$\alpha$ & expected future inflation & $\begin{array}{l}0.2320 \\
(0.3482)\end{array}$ & $\begin{array}{l}0.5217 \\
(0.0162)\end{array}$ & $\begin{array}{l}0.4727 \\
(0.0240)\end{array}$ & $\begin{array}{l}0.5298 \\
(0.0168)\end{array}$ \\
\hline$\kappa$ & output gap elasticity & $\begin{array}{l}0.0237 \\
(0.0231)\end{array}$ & $\begin{array}{l}0.0057 \\
(0.0040)\end{array}$ & $\begin{array}{l}0.0032 \\
(0.0029)\end{array}$ & $\begin{array}{l}0.0015 \\
(0.0056)\end{array}$ \\
\hline$\theta$ & lagged natural output & $\begin{array}{l}0.9046 \\
(0.0128)\end{array}$ & $\begin{array}{l}0.9296 \\
(0.0152)\end{array}$ & $\begin{array}{l}0.9107 \\
(0.0116)\end{array}$ & $\begin{array}{l}0.9273 \\
(0.0155)\end{array}$ \\
\hline$\eta_{y}$ & demand shock feedback & $\begin{array}{l}0.4307 \\
(0.0901)\end{array}$ & $\begin{array}{l}1.2176 \\
(0.1986)\end{array}$ & $\begin{array}{l}0.3224 \\
(0.0798)\end{array}$ & $\begin{array}{l}0.4649 \\
(0.0711)\end{array}$ \\
\hline$\chi$ & Okun coefficient & $\begin{array}{l}0.3582 \\
(0.0237)\end{array}$ & $\begin{array}{l}0.4578 \\
(0.0577)\end{array}$ & $\begin{array}{l}0.3843 \\
(0.0327)\end{array}$ & $\begin{array}{l}0.4641 \\
(0.0583)\end{array}$ \\
\hline$\delta$ & loss discount factor & $0.99^{*}$ & $0.99^{*}$ & $0.99^{*}$ & $0.99^{*}$ \\
\hline$\lambda_{y}$ & output gap weight & $\begin{array}{l}0.3232 \\
(0.1103)\end{array}$ & $\begin{array}{l}0.4242 \\
(0.3510)\end{array}$ & $\begin{array}{l}0.2687 \\
(0.1196)\end{array}$ & $\begin{array}{l}0.1478 \\
(0.5042)\end{array}$ \\
\hline$\lambda_{i}$ & interest-rate smoothing weight & $\begin{array}{r}1.6568 \\
(0.5735)\end{array}$ & $\begin{array}{r}0.7382 \\
(0.4440) \\
\end{array}$ & $\begin{array}{r}0.7578 \\
(0.5318) \\
\end{array}$ & $\begin{array}{r}0.1552 \\
(0.5258) \\
\end{array}$ \\
\hline $\ln \mathcal{L}$ & log likelihood & -725.2954 & -447.8649 & -671.2532 & -445.1656 \\
\hline
\end{tabular}

Notes: The table reports maximum-likelihood estimates of Eqs. (C.1), (C.2), and (3) - (10) as well as estimates of Eqs. (1) (10). In both cases the partial and complete information estimates are reported. Numbers in parentheses are standard errors. * denotes a value that is imposed prior to estimation. 
(a): $\Delta y_{t}$

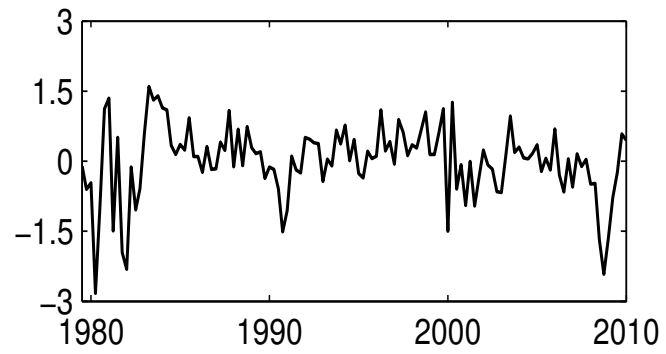

(c): $\Delta y_{t}^{0}-\Delta y_{t}$

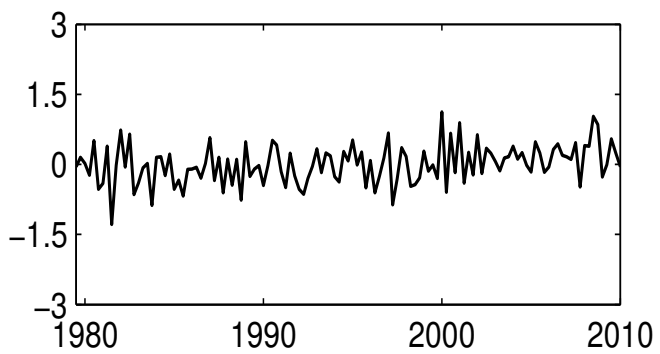

(e): $\Delta u_{t}$

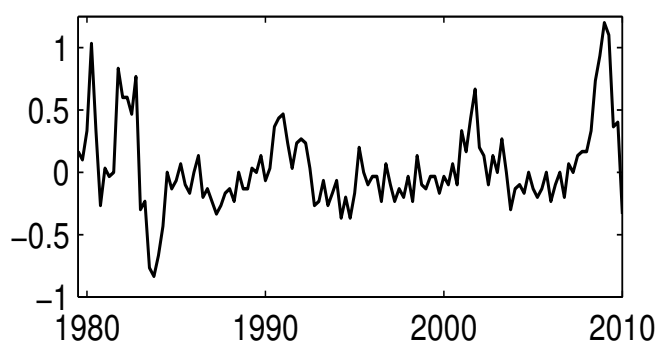

(b): $\pi_{t}$

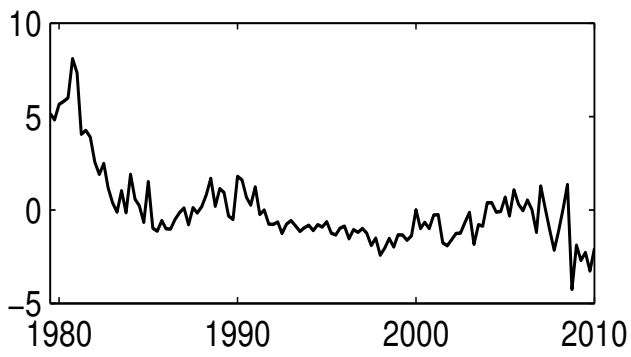

$(\mathrm{d}): \pi_{t}^{0}-\pi_{t}$

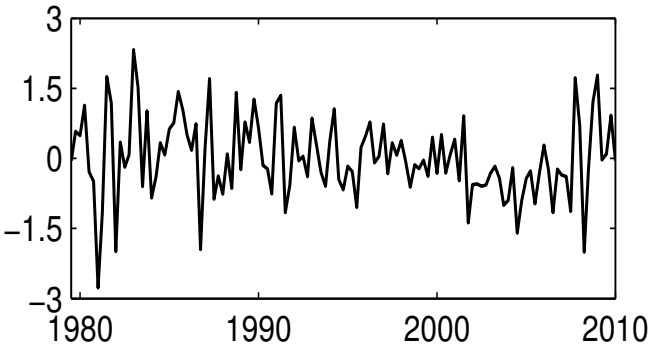

(f): $i_{t}$

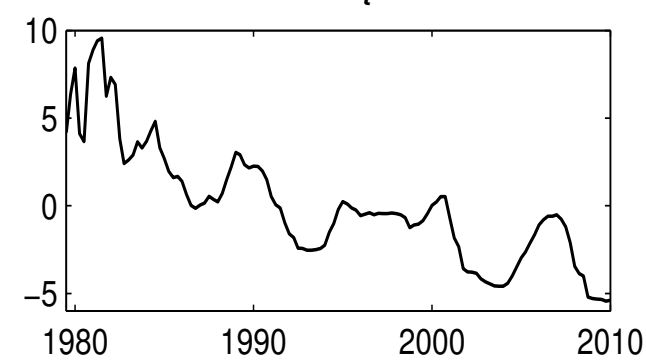

Fig. 1. Panels (a) and (b) plot the ex post revised series for per capita real GDP growth, $\Delta y_{t}$, and GDP inflation, $\pi_{t}$. Panels (c) and (d) plot the series of historical revisions to real-time per capita GDP growth, $\Delta y_{t}^{o}-\Delta y_{t}$, and GDP inflation, $\pi_{t}^{o}-\pi_{t}$. Panels (e) and (f) plot changes in the civilian unemployment rate, $\Delta u_{t}$, and the annual yield on 3-month US Treasury bills, $i_{t}$. 


\section{(a): Actual and Perceived Output Gap}

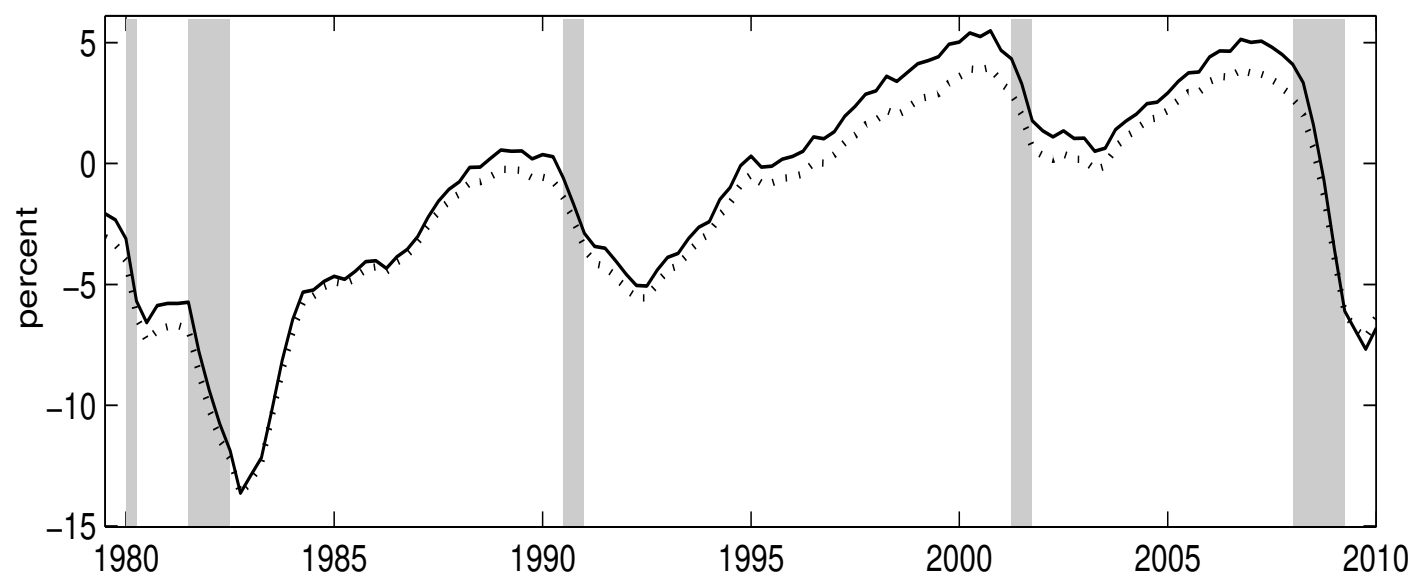

(b): Real-Time Perception Errors

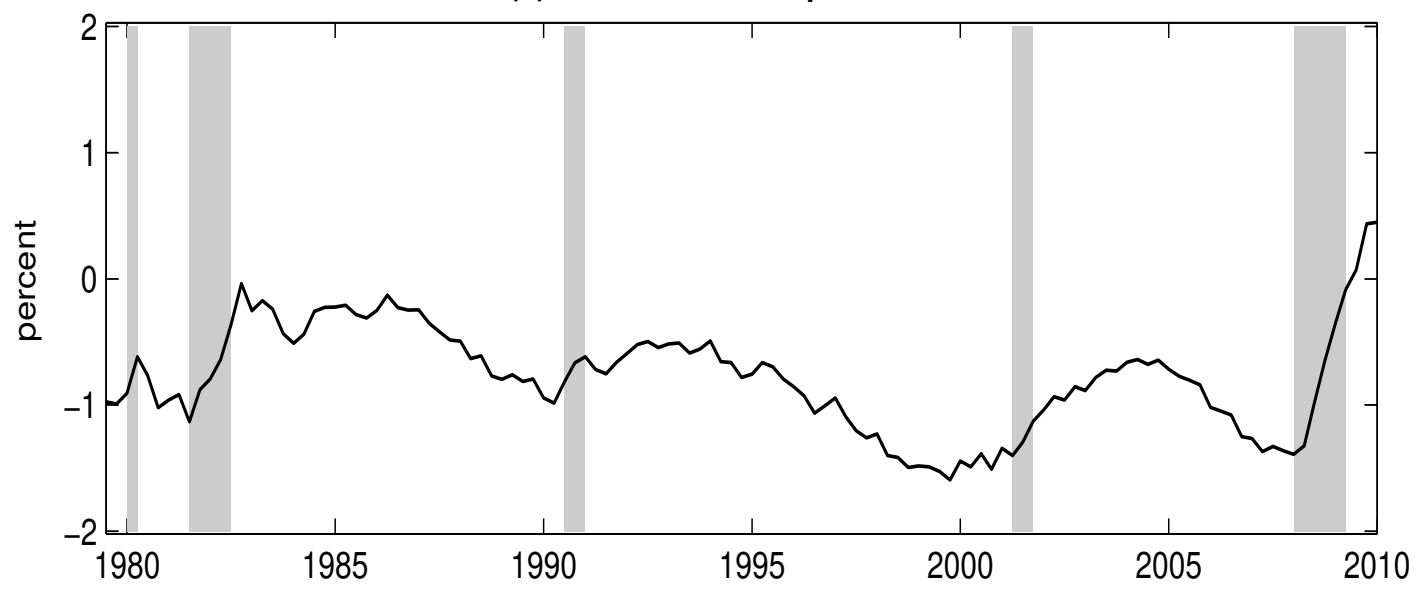

Fig. 2. Panel (a) plots the estimates of the actual output gap ( $q_{t} \equiv y_{t}-y_{t}^{n}$, solid line) and the perceived output gap $\left(q_{t \mid t} \equiv y_{t \mid t}-y_{t \mid t}^{n}\right.$, dotted line) obtained from the Kalman smoother. Panel (b) plots estimates of the implied real-time perception errors, $q_{t \mid t}-q_{t}$. The shaded regions correspond to NBER recessions. 
(a): Actual and Perceived Inflation

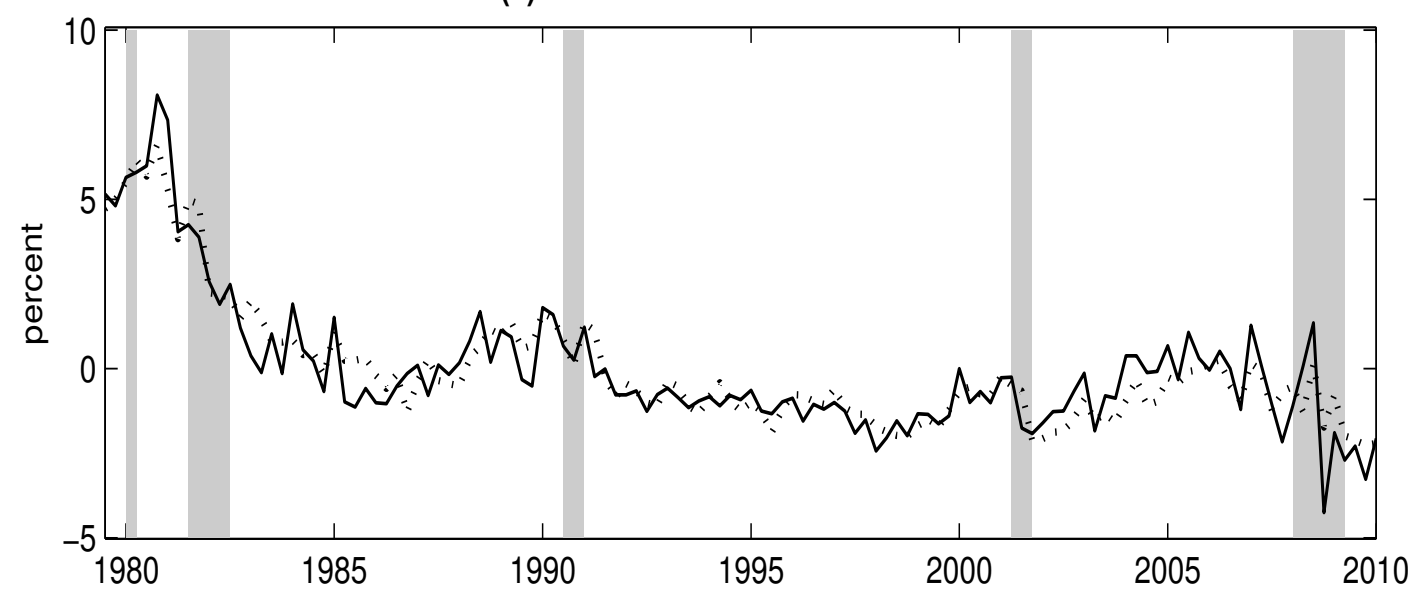

(b): Real-Time Perception Errors

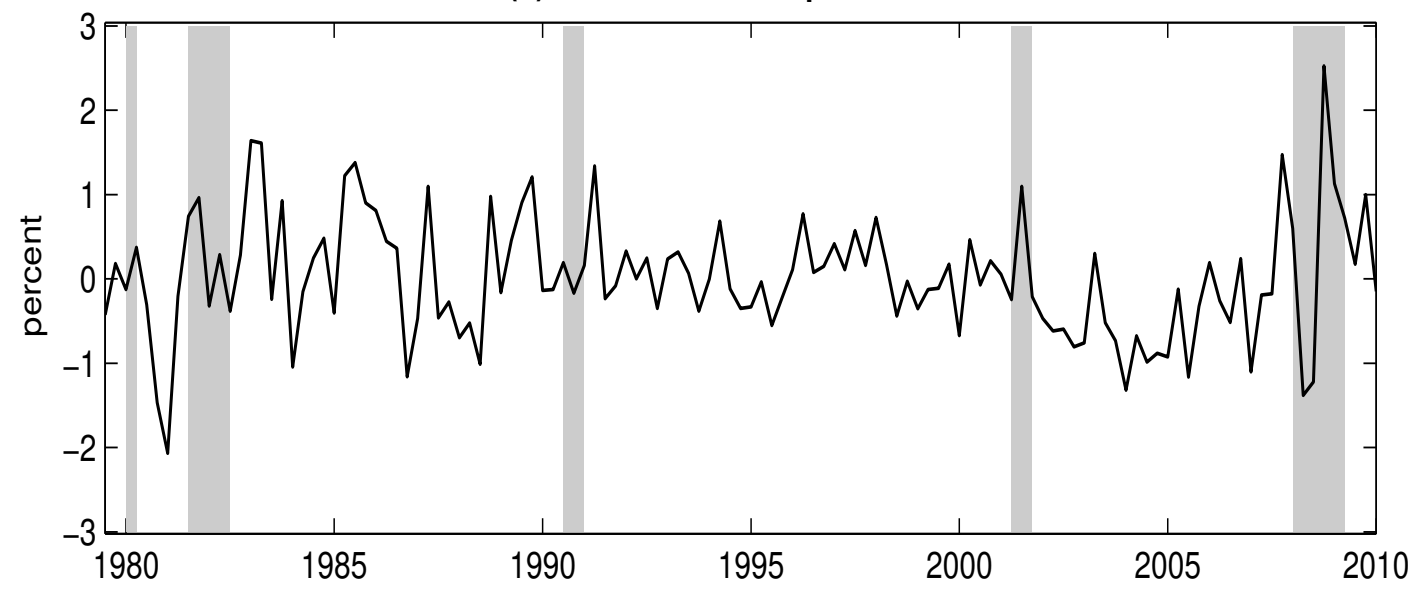

Fig. 3. Panel (a) plots the estimates of actual inflation $\left(\pi_{t}\right.$, solid line) and perceived inflation $\left(\pi_{t \mid t}\right.$, dotted line) obtained from the Kalman smoother. Panel (b) plots estimates of the implied real-time perception errors, $\pi_{t \mid t}-\pi_{t}$. The shaded regions correspond to NBER recessions. 